
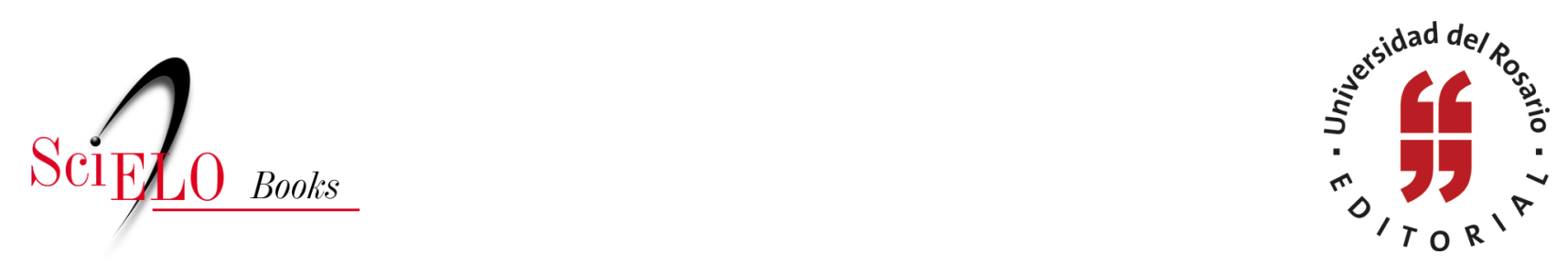

\title{
Capítulo 3. La información catastral como reflejo de la diferenciación socioeconómica urbana y su carácter multifinalitario
}

\author{
Leonardo Bernal \\ Fabio Tejedor
}

\section{SciELO Books / SciELO Livros / SciELO Libros}

BERNAL, L., and TEJEDOR, F. La información catastral como reflejo de la diferenciación socioeconómica urbana y su carácter multifinalitario. In: SEPÚLVEDA RICO, C.E., LÓPEZ CAMACHO, D., and GALLEGO ACEVEDO, J.M., eds. Los límites de la estratificación: en busca de alternativas [online]. Bogotá: Editorial Universidad del Rosario: Alcaldía Mayor de Bogotá D.C., 2014, pp. 41-82. ISBN: 978-958-738-537-3. https://doi.org/10.7476/9789587385373.0005.

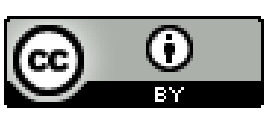

All the contents of this work, except where otherwise noted, is licensed under a Creative Commons Attribution 4.0 $\underline{\text { International license. }}$

Todo o conteúdo deste trabalho, exceto quando houver ressalva, é publicado sob a licença Creative Commons Atribição 4.0.

Todo el contenido de esta obra, excepto donde se indique lo contrario, está bajo licencia de la licencia Creative Commons Reconocimento 4.0 . 


\title{
Capítulo 3 \\ La información catastral como reflejo de la diferenciación socioeconómica urbana y su carácter multifinalitario
}

\author{
Leonardo Bernal y Fabio Tejedor*
}

Palabras clave: avalúo catastral, información catastral, valor unitario integral, diferenciación socioespacial, renta del suelo urbano, mercado de tierras, precio del suelo, diferenciación socioeconómica, modelos lineales generalizados, estratificación socioeconómica.

\section{Introducción}

Apartándose de la óptica meramente instrumental con propósitos fiscales que se le ha atribuido históricamente, una mirada conceptual más profunda reviste a la información catastral de unas cualidades y propiedades técnicas que le significan un potencial superior, no solo como espejo e inventario multidimensional de la configuración y actualidad urbanística, sino además como fuente de información técnica y objetiva para los múltiples propósitos de la gestión estatal, entre ellos, la formulación de políticas redistributivas para la prestación y cobro de los servicios públicos domiciliarios (SPD).

* Consultores independientes. 
En la primera parte de este capítulo, se propone una perspectiva analítica que, con base en la lógica y características del mercado de tierras y los mecanismos de formación y realización de la renta del suelo, permite relacionar los diferenciales de precios del suelo (cristalizados en el avalúo catastral) con las condiciones socioeconómicas de quienes acceden a él, quienes, según su desigual capacidad de pago, pueden o no acceder y usufructuar determinada localización intraurbana, determinado tipo de vivienda y ciertas condiciones asociadas de hábitat, entorno urbanístico y calidad de vida urbana; disímiles y dispares en cada sector de la ciudad. Dicha perspectiva expone los argumentos necesarios para comprender que todas aquellas diferencias concretadas y materializadas en los precios del suelo pueden constituir, a través de la información catastral, un nuevo conjunto de variables apropiadas para la diferenciación, clasificación y agrupación de los domicilios y fuente de información para la estratificación socioeconómica; o como base de un instrumento (modelo) sustitutivo para administrar y focalizar, sin la existencia de estratos, las acciones redistributivas en materia de provisión de SPD.

En un segundo apartado, se desarrolla la base argumentativa que sustenta que la información catastral y, específicamente el avalúo catastral, es un instrumento de gran relevancia para detectar, capturar, sintetizar y reflejar las diferenciación morfológica, urbanística y socioeconómica existente en el parque inmobiliario residencial de la ciudad, y se presentan algunos resultados empíricos que confirman la relación existente entre el avalúo catastral y los estratos socioeconómicos vigentes.

Ante la necesidad de identificar los impactos de una posible clasificación de domicilios con base en la información catastral que sea independiente de la estratificación socioeconómica actual, en el tercer apartado, se exponen los resultados empíricos de la medición del efecto actual del estrato en la fijación de los avalúos catastrales, a fin de proponer a posteriori algunas recomendaciones de política pública que determinen la eliminación de dicha variable en los procesos catastrales y las actividades valuatorias masivas en el Distrito Capital, siendo un instrumento igualmente consistente que permite capturar la diferenciación socioeconómica sin el efecto cíclico del estrato en el cálculo del avalúo y su posterior uso como herramienta de diferenciación.

Este capítulo finaliza proponiendo una variable que sintetice el valor de construcción del metro cuadrado tanto de predios de propiedad horizontal (PH) como de no PH, debido a que la diferencia en los tamaños de los terre- 
nos hace que el valor de construcción para ambos tipos no sea comparable entre sí. El valor unitario integral del avalúo tiene en cuenta tanto el área de la construcción como del terreno asignado. Esta variable propuesta pasa a ser la variable catastral representativa en las estimaciones a lo largo de este libro y es el insumo central en las diferentes estimaciones de los capítulos.

\subsection{Información catastral como fundamento posible de clasificación de domicilios y fuente para una metodología de estratificación}

\subsubsection{GENERALIDADES SOBRE EL SISTEMA CATASTRAL EN El Distrito CAPITAL}

Existen numerosas aproximaciones conceptuales que definen el propósito y los componentes de los sistemas catastrales. Según el Comité Permanente sobre el Catastro de la Unión Europea (Permanent Committe on Cadastre, 2003), la actividad catastral tiene por finalidad la creación y mantenimiento de la información alfanumérica y gráfica asociada a las parcelas, así como sus agregaciones. Debe contribuir a mejorar la eficacia y eficiencia de la administración del territorio ofreciendo información técnica en el ámbito de los derechos de la propiedad, la tributación inmobiliaria y la gestión del territorio, así como la provisión de servicios que permitan la interoperabilidad de las bases de datos necesarias para actividades específicas.

Dicho propósito atribuido al sistema catastral, para el caso de los países de América Latina, donde la mayoría de los catastros se encuentran centralizados y estatalizados, se cumple registrando esencialmente tres tipos de datos según el modelo económico-físico-legal tradicional: el valor económico, la ubicación y forma de la parcela (como célula básica del territorio), y la relación entre la propiedad y el propietario u ocupante (Erba, 2004).

Particularmente en el caso colombiano, la Resolución 70 de 2011 del Instituto Geográfico Agustín Codazzi ${ }^{1}$ (IGAC) se encuentra alineada con las citadas percepciones y establece que "el catastro es el inventario o censo, de-

\footnotetext{
El IGAC es la máxima autoridad catastral en Colombia y administra el Sistema Nacional Catastral en todo el territorio nacional, a excepción del departamento de Antioquia y las ciudades de Bogotá, Medellín y Cali, cuyos catastros son descentralizados y administrados por las respectivas autoridades territoriales.
} 
bidamente actualizado y clasificado, de los bienes inmuebles pertenecientes al Estado y a los particulares, con el objeto de lograr su correcta identificación física, jurídica, fiscal y económica" (IGAC, 2011).

En la literatura especializada, se encuentran otras acepciones que enriquecen la noción de un sistema catastral integrado con carácter multifinalitario que conjugue la información del registro y de la propiedad de los bienes inmuebles urbanos, especificando sus características físicas, las condiciones urbanísticas de su entorno circundante, la provisión de bienes y servicios públicos, las particularidades ambientales, socioeconómicas y demográficas; cuya finalidad sea la de constituir una herramienta holística de planificación, que pueda emplearse en distintas escalas para enfrentar los desafíos de la expansión urbana, las dinámicas demográficas, el ordenamiento territorial, la lucha contra la pobreza, las políticas de suelo y el desarrollo económico sostenible, entre otros².

En el Distrito Capital, la Unidad Administrativa Especial de Catastro Distrital (UAECD) es la entidad oficial encargada de la gestión del sistema catastral de Bogotá y su principal función misional es realizar los tres procesos que conforman y mantienen la base de información física, jurídica y económica del parque inmobiliario de Bogotá: la formación catastral, la actualización de la formación y la conservación del catastro. Cada uno de estos procesos está encaminado a recolectar la información de los predios en el interior de la unidad orgánica catastral (el Distrito Capital, en este caso) y difieren según el momento, alcance y objetivo de su ejecución.

Describir a profundidad cada uno de los aspectos conceptuales, técnicos y operativos de los procesos catastrales que se desarrollan en Bogotá es una labor extensa y compleja, que escapa al objetivo de este capítulo. Sin embargo, en el propósito de presentar al lector los objetivos, las variables, la estructura general y los productos finales del sistema catastral, expondremos de forma general y sintética las etapas que conforman dichos procesos y su alcance.

En la formación y/o actualización catastral, se llevan a cabo una serie de subprocesos secuenciales que conducen a la caracterización detallada sobre

2 Al respecto, ver la Declaración de Bogor, la Declaración de Bathurst, Declaración de la FIG, Declaración del Comité de Catastro de la Unión Europea y Visión Catastro 2014; todas ellas sintetizadas en Erba y Águila (2007). 
los aspectos físicos, jurídicos y económicos de cada predio inscrito (o por inscribir) en la base de datos, y comprende:

a) Revisión de la información secundaria disponible en la UAECD y cruce de archivos alfanuméricos y cartográficos de cada predio, con el objetivo de diagnosticar predios no coincidentes en la base catastral, en el registro y en la cartografía, corroborar la situación jurídica actual del predio en el registro inmobiliario (detectar transferencias de dominio no incorporadas en la base catastral o segregaciones) y construir los reportes con la identificación de las variables físicas (p. e., diferenciales de áreas y/o medidas entre las dos bases, errores en la base catastral) que serán objeto de verificación en el terreno, por parte de los técnicos de reconocimiento predial.

b) Recolección de información primaria (censo o reconocimiento predial) en cada uno de los sectores, manzanas y predios identificados como objeto de formación o actualización catastral en la correspondiente vigencia ${ }^{3}$. Las variables que en cada uno de los predios se revisan y renuevan al momento del reconocimiento predial son:

- La localización del predio, a través de la nomenclatura vial y domiciliaria (dirección).

- Medición de áreas de terreno y áreas construidas, delimitadas por niveles (pisos o plantas) y discriminadas de acuerdo con el uso específico de la construcción (residencial, comercial, institucional, industrial, dotacional, mixto, etc.). Registro de características físicas particulares y construcciones anexas (patios, terrazas cubiertas, antejardines, sótanos, semisótanos, voladizos, aleros, retrocesos, balcones, etc.).

- Calificación de las especificaciones constructivas y arquitectónicas de cada unidad construida del predio, por cada uso encontrado. Para el efecto, el funcionario utiliza un formato denominado 'ficha predial' en el que se consignan puntajes numéricos que evalúan

La Ley 14 de 1983 estableció períodos de cinco años para la actualización del catastro. Dicha vigencia de la información catastral y el plazo para la actualización fueron revalidados por el artículo 24 de la Ley 1450 de 2011 - Plan Nacional de Desarrollo. 
mejores o peores condiciones en cuanto a cimentación, materiales de construcción, tamaños, calidades, mobiliarios y estados de conservación (mantenimiento) de los principales componentes físicos de la unidad construida, desagregados en 16 variables que para el caso residencial se agrupan en cuatro categorías o ítems: estructura, acabados principales, baños y cocina.

Así mismo, en la 'ficha predial', se registran la edad de la construcción o los porcentajes de avance de la obra (en el caso de proyectos no terminados), el destino económico del predio (actividad para la que fue proyectado) y si el predio se encuentra o no bajo el régimen de propiedad horizontal.

- La información jurídica del predio, a través de un formulario que previamente se ha entregado al propietario o poseedor ${ }^{4}$ y que debe quedar consignada en la 'ficha predial' que contiene los espacios necesarios para corroborar el número de propietarios, la identificación de cada propietario actual, el tipo de documento de adquisición de la propiedad (escritura, resolución administrativa de adjudicación, sentencia judicial, declaración extrajuicio, etc.), el folio de matrícula inmobiliaria, el régimen de propiedad (régimen de propiedad horizontal, condominio o sin restricciones a la propiedad), el código del (los) predio(s) matriz(ces), entre otros. Esta investigación usualmente involucra la revisión de los documentos jurídicos en las notarías correspondientes.

- La información de casos especiales, como los predios dispersos (no tienen soporte jurídico para su desenglobe y solo se conoce la información del predio matriz del cual fueron segregados física mas no jurídicamente), los predios sobrantes (existen jurídicamente en la base catastral pero no es posible ubicarlos en el terreno), los predios conservados indefinidos (predios inicialmente omitidos en

4 Según la UAECD: "Propietario o poseedor se diferencian porque el propietario es aquel que puede sustentar este título mediante una escritura pública debidamente registrada. El poseedor es aquel que generalmente demuestra su posesión con una promesa de compraventa, con los pagos de los servicios públicos (a nombre de este último), con declaraciones extrajuicio, con escrituras de protocolización de mejoras, etc. y donde no se conoce cuál es el verdadero propietario, por no disponer de información jurídica. Comúnmente los poseedores se encuentran realizando juicio de pertenencia” (UAECD, 2006, p. 15). 
el proceso de formación) y los predios correspondientes a cesiones de vías.

c) Transcripción, control de calidad, validación de datos y digitalización de la información alfanumérica y cartográfica del censo (reconocimiento) predial.

d) Determinación de las zonas homogéneas físicas (ZHF), definidas como espacios geográficos dentro del perímetro urbano con características físicas similares (u homogéneas) que les permiten diferenciarse de sus adyacentes. En esta etapa, se considera la superposición de cartografías a escalas 1:1.000 o 1:2.000, en las que se ilustran tres categorías y ocho variables consideradas fundamentales para la determinación del valor del terreno: Norma de uso del suelo (variables: clase de suelo, área de actividad, tratamiento), adecuación al uso urbano (variables: topografía, vías, servicios públicos) y usos de los inmuebles de la zona (variables: actividades económicas predominantes en los inmuebles y tipo según actividad del inmueble).

Cada zona homogénea física (ZHF) en el interior de la ciudad se delimita y codifica a partir de las áreas que presenten homogeneidad relativa a las ocho variables mencionadas, y denotan mejores o peores condiciones urbanísticas, de potencial de desarrollo de actividad edificadora, de acceso a infraestructura, bienes y servicios públicos, así como de aglomeración y magnitud de actividades económicas predominantes; todos ellos factores condicionantes en la formación de precios del suelo urbano. El plano de las ZHF se considera un plano inicial, siendo un insumo fundamental para la determinación de las zonas homogéneas geoeconómicas (ZHG).

e) Delimitación de las zonas homogéneas geoeconómicas (ZHG), definidas como los sectores dentro del perímetro urbano que presentan características físicas similares y precios equiparables (isoprecios), cuyas diferencias pueden ser despreciables. En dichas zonas, los precios o valores unitarios (por metro cuadrado) de terreno son hallados mediante la práctica de avalúos comerciales puntuales en predios seleccionados como una muestra representativa de cada ZHG, considerando el comportamiento del mercado inmobiliario local de forma directa e indirecta, y, por otro lado, los valores unitarios de construcción 
(o integral, en el caso de predios bajo régimen de propiedad horizontal) corresponden a la estimación individual proveniente de los modelos econométricos que relacionan, entre otras, las variables de la ficha predial arriba mencionada que describen categóricamente las características físicas de cada inmueble, el valor unitario del terreno según la ZHG, la posible mezcla y participación de cada uso que se desarrolla en el terreno del predio y la dinámica de las actividades económicas que tienen lugar dentro de la ZHG correspondiente.

La determinación de zonas homogéneas en sus características físicas y, en su interior, áreas de precios del suelo similares que son recogidas por el avalúo catastral, se deriva de las especificidades físicas, incluidas las dotaciones de las que disponen las zonas, que se refleja en el mercado de suelo. Tal es el sustento de las técnicas de valuación inmobiliaria masiva ${ }^{5}$.

f) Avalúo catastral, que, de acuerdo con la Resolución 70 de 2011 del IGAC, "consiste en la determinación del valor de los predios, obtenido mediante investigación y análisis estadístico del mercado inmobiliario. El avalúo catastral de cada predio se determinará por la adición de los avalúos parciales practicados independientemente para los terrenos y para las edificaciones en él comprendidos”. A partir de esta definición y una vez realizadas las estimaciones de los valores unitarios de terreno y de construcción (según cada uso presente en el predio), el avalúo catastral del predio resulta de sumar el avalúo del terreno (producto entre valor unitario -valor $\mathrm{x}^{2}$ - de terreno y el área del terreno) y el avalúo de la construcción (sumatoria de los productos del valor uni-

5 La zonificación permite establecer las diferencias (naturales y creadas individual y colectivamente) tanto en el suelo y las construcciones como en los entornos diferenciados (por localización, infraestructura de servicios y vialidad, condiciones topográficas, urbanísticas, arquitectónicas y otros aspectos subjetivos y perceptuales). Los procesos técnicos de determinación de zonas y las variables que las configuran se sitúan en prácticas empleadas de larguísimo tiempo en la planificación urbana, particularmente en la definición de áreas urbanas sobre las cuales se requiere un tipo particular de intervención con políticas diferenciadas. Cuando resulta imposible realizar un número muy alto de avalúos singulares, se recurre a la valuación masiva. Con esta, la zonificación constituye un aspecto muy importante para la determinación de valores de referencia que, junto a diversas variables, alimentan los modelos econométricos utilizados para la determinación del valor de predios individuales que, a su vez, constituyen la base para el cálculo de cargas fiscales e impuestos relativos a la propiedad inmobiliaria. 
tario de construcción, según cada uso) y el área construida destinada a cada uso.

Así, el avalúo catastral es resultado acumulativo de las etapas mencionadas y resulta ser uno de los productos fundamentales de los procesos catastrales mencionados (formación, actualización y conservación). Individualmente, es capaz de recoger y sintetizar las disímiles calidades, especificaciones y técnicas de construcción, la mayor o menor inversión en materiales, acabados y conservación de los inmuebles, la disponibilidad de mayor o menor área privada para la actividad residencial, las posibilidades de uso exclusivo de bienes y servicios suntuarios en el interior de las urbanizaciones y toda la influencia de la especulación rentística asociada a condiciones diferenciales de localización, accesibilidad a bienes y servicios públicos, cercanía a centralidades, acceso a infraestructuras de transporte y movilidad e, incluso, mejores condiciones paisajísticas y ambientales. Todas las variables físicas del inmueble que se capturan en la ficha predial y las variables que influyen en la zonificación urbana (ZHF y ZHG), por mencionar solo algunas, son afluentes que enriquecen y configuran, desde diversas ópticas y en distinta medida, al avalúo catastral.

\subsubsection{INFORMACIÓN CATASTRAL COMO INSTRUMENTO PARA CAPTAR LA DIFERENCIACIÓN SOCIOECONÓMICA Y LAS RENTAS DEL SUELO: ELEMENTOS CONCEPTUALES}

Desde una perspectiva analítica, en el presente apartado, se examinan y exponen las propiedades de la información catastral y específicamente del avalúo catastral para captar y sintetizar la diferenciación socioeconómica urbana, reflejada en los diferenciales de los precios del mercado inmobiliario a los que un morador puede o no acceder, en función de su mayor o menor capacidad de pago. Así mismo, una mayor comprensión de dichas propiedades y características técnicas permitirá sustentar el uso del avalúo catastral (y su íntima asociación con la capacidad de pago de los hogares) para acciones redistributivas en servicios públicos domiciliarios (SPD).

En el propósito de recoger y capturar la diferenciación socioeconómica a nivel predial que requiere la estratificación o cualquier otro instrumento para administrar y/o focalizar los subsidios y las contribuciones en servicios públicos domiciliarios, la mejor opción sería utilizar la capacidad de pago de los hogares, pero esta información está lejos de estar disponible al nivel de 
detalle requerido ${ }^{6}$. De forma alternativa, como se profundizó en el capítulo 2 de esta obra, diversos estudios, como los de Econometría ${ }^{7}$ (1999), Sardi ${ }^{8}$ (2007, 2008), DANE (2011) y González (2013), han señalado y puesto de relieve las potencialidades de la información catastral como insumo para captar la diferenciación socioeconómica y las múltiples correspondencias, tanto conceptuales como empíricas, de las variables catastrales con la capacidad de pago de los hogares.

Dentro del contexto de la literatura mencionada, se podría pensar en las amplias posibilidades que tendría una clasificación de los domicilios a partir de la información catastral y, específicamente a partir del avalúo catastral de los inmuebles residenciales, para reflejar la desigual capacidad económica de los hogares, los diferenciales de calidad de vida urbana en el interior de la ciudad, contribuir en mayor o menor medida a la reducción de los actuales errores de inclusión y exclusión en el sistema cruzado de subsidios y contribuciones, y servir como soporte preciso, objetivo, conceptualmente sólido y actualizado para focalización del gasto público en $\mathrm{SPD}^{9}$ o para introducir mejoras en las

6 González (2013, p. 86) afirma: "Sin duda, en el país todavía se está lejos de contar con un sistema de información que permita conocer la capacidad de pago de las personas. Este ideal únicamente se conseguiría cuando la información sobre el ingreso sea universal, y supere el ámbito de las necesidades tributarias. Mientras no se tenga información sobre los ingresos de las personas, no será posible determinar la política de subsidios y de tarifas en función de la capacidad de pago".

7 En el estudio se señala: "En general se puede concluir que la estratificación actual no refleja la estructura de avalúos catastrales de las viviendas de diferentes estratos. Lo cual se debe principalmente a que la zonificación utilizada para llevar a cabo el procedimiento de estratificación respondía a conceptos urbanísticos y socioeconómicos del entorno (zonas de hábitat), evaluados con un alto grado de subjetividad y no a una zonificación basada en información catastral, como era la metodología alternativa".

8 Las conclusiones de Sardi indican que los resultados de la correlación canónica no lineal muestran una fuerte asociación entre el conjunto de variables de clasificación de los hogares y el conjunto de variables de calificación de las edificaciones y las zonas homogéneas, lo cual muestra la factibilidad de utilizar este tipo de procedimiento con el fin de garantizar el blindaje de los resultados de la estratificación que minimiza la posibilidad de intervenciones externas para modificar la realidad de las cabeceras municipales, generando riesgo al sistema. Otro aspecto es que se garantiza la calidad de la información, así como reducir los costos de recolección de la información por parte de los entes territoriales, considerando que es competencia del IGAC. Es importante garantizar por parte del IGAC la actualización de las variables de calificación de las edificaciones con uso vivienda, en sus definiciones y su asignación a opciones de respuestas que garanticen el carácter ordinal de esta, así como actualizar el modelo econométrico que define las zonas homogéneas económicas y físicas (Sardi, 2007, p. 40).

9 Según González, "después de la capacidad de pago, los avalúos son la segunda mejor opción para 
metodologías de estratificación socioeconómica en la ciudad. No obstante, se requiere una mayor certeza conceptual que permita profundizar en sus especificidades y robustecer el sustento de su aplicación.

A manera de antecedente, vale la pena recordar que el catastro colombiano desde el momento mismo de su génesis fue concebido como un instrumento para asignar cargas tributarias que se aproximasen a la capacidad de pago de los propietarios residentes en los asentamientos humanos durante el siglo XIX. Con la expedición de la Constitución Política de 1821 y la posterior ley del 30 de septiembre del mismo año, el denominado ‘Catastro General del Cantón' apoyó los propósitos fiscalistas del gobierno de la Gran Colombia para la financiación y sostenimiento de la guerra de independencia (Ramos et al., 2004). La sinapsis del Catastro con las condiciones económicas de los hogares siempre ha existido, pero quizás en la gestión pública y en la formulación de políticas diferenciales aún no se le ha sacado mayores réditos.

Desde un punto de vista más conceptual, uno de los desarrollos teóricos que resulta útil para examinar la asociación 'capacidad de pago-avalúo catastral' y sus propiedades para captar diferenciación socioeconómica es el de Samuel Jaramillo (1994), en donde la teoría de la renta del suelo urbano aborda el concepto de tierra urbana y de la generación del espacio urbano construido, se exponen las características de los procesos de acumulación capitalista a los cuales se liga la tierra urbana y se identifican las dinámicas que constituyen su articulación compleja para la generación de rentas.

Jaramillo (1994) analiza los procesos de transformación que la tierra experimenta en las ciudades, y los procesos productivos y vitales a los cuales da soporte, diferenciando articulación primaria y secundaria de la tierra urbana. En primer lugar, la tierra entra en conexión con un proceso productivo, la construcción, lo que se denomina articulación primaria de la tierra urbana. En segundo término, en virtud de la inmovilidad del producto, la tierra entra además en relación con un conjunto de otras actividades urbanas complementarias que requieren del espacio construido para su operación. Se trata de las actividades urbanas con las cuales la tierra se relaciona a través del consumo del 'espacio construido'. A esto se denomina articulación secundaria

orientar las políticas públicas. Los avalúos de Bogotá ya están, en promedio, cerca al $80 \%$ del valor comercial de los inmuebles. Deberían ser el referente para fijar las tarifas de los servicios públicos. Es una solución subóptima ya que son mejores que el estrato, pero no son tan buenos como la capacidad de pago" (González, 2013, p. 87). 
de la tierra urbana. Los inmuebles se destinan a procesos muy variados, como el comercio, la vivienda, la industria, los equipamientos públicos, etc., y las características espaciales de las tierras que soportan estas edificaciones son decisivas para la realización y desempeño de estas actividades, determinando sus potencialidades. Son precisamente estas circunstancias las que permiten la emergencia de dos tipos de rentas: “(...) en la tierra urbana, dada esta articulación compleja (articulación primaria, articulación secundaria) aparecen dos familias de rentas: las rentas primarias asociadas a la construcción, y las rentas secundarias, ligadas a las actividades o 'usos urbanos'. Las dos influyen y se entrelazan para modular los precios de los terrenos de la ciudad" (Jaramillo, 2003, p. 20).

De acuerdo con Jaramillo (1994), las articulaciones primaria y secundaria de la tierra urbana modulan los precios de mercado de suelo urbano y estos, a su vez, recogen las rentas generadas en la conexión entre la tierra, el proceso productivo de la construcción y las interacciones constantes con los sectores urbanos que aglomeran usos complementarios que dan soporte a la actividad residencial (comercio, industria, dotacionales e infraestructura, entre otros, lugares denominados 'centralidades'). En tal sentido, resultaría intuitivo pensar que la diferenciación de precios directamente condiciona las posibilidades de acceso a habitantes, según su mayor o menor capacidad de pago, para alcanzar dicho precio y participar en el mercado de suelo. A su vez, esta diferenciación en el mercado inmobiliario obedece a la desigual dotación de recursos o características físicas de los terrenos y espacios construidos (la localización, la topografía, la dotación de servicios, la capacidad portante, la infraestructura vial y condiciones urbanísticas, arquitectónicas y de hábitat), que dan origen a las rentas diferenciales. Estas rentas, de manera abstracta y en su orden, se especifican como renta absoluta (asociada al hecho mismo de la propiedad); renta diferencial I y II (asociadas respectivamente a la capacidad portante y a la ubicación, y a la inversión de capital); y renta de monopolio (asociada a la demanda del producto final - tipos específicos de construcciones y de entornos ambientales urbanos) (Jaramillo, 2009).

Se puede comprender entonces que el avalúo catastral de los inmuebles residenciales, cuyo origen se funda en el comportamiento de los precios del mercado inmobiliario local y cuya concepción sintetiza y conjuga una gran parte de las variables levantadas en los procesos catastrales, es el instrumento mediante el cual se captura la diversidad de calidades, técnicas y especifica- 
ciones constructivas, se recoge la mezcla de usos, se refleja la multivariada diferenciación de los sectores urbanos exhibida en la zonificación urbana (ZHF y ZHG), se capturan las diferentes rentas originadas por la articulación primaria y secundaria de la tierra, y se clasifican las áreas urbanas según su valor de cambio; este último vinculado estrechamente con el nivel de ingreso disponible (o capacidad de pago) que los habitantes deben detentar para poder hacerse a mejores o peores características arquitectónicas, de hábitat, de entorno urbanístico, ambientales y paisajísticas.

Como referimos en el apartado anterior, la información que se levanta en los procesos catastrales constata la diferenciación existente en el tipo de viviendas que los usuarios de suelo habitacional adquieren según la calidad constructiva, el tipo de materiales utilizados, el área construida, el mobiliario, las características de sus acabados principales, la edad (vetustez) y el estado de conservación, que reflejan la capacidad que tienen sus propietarios u ocupantes para pagar por las calidades y comodidades que cada tipo de construcción ofrece, o, en la otra dirección, para renunciar a ellas y demandar viviendas de calidad inferior que se ajusten a su capacidad real de pago. Al respecto, el grupo de diseño metodológico de estratificación del DANE señala:

\begin{abstract}
No se accede a una vivienda de mejores especificaciones constructivas o de mejor localización geográfica fundamentalmente por limitaciones en la disponibilidad para pagar por ella, ni se vive en una vivienda peor o en un área pobremente dotada motivado por la obtención de subsidios públicos. La racionalidad de la elección del tipo de vivienda, sus características, su dotación de servicios y su localización relativa en el espacio urbano estriba esencialmente en la capacidad económica, el nivel de ingreso o en la capacidad de pago de los hogares (DANE, 2011, p. 23).
\end{abstract}

La lógica de los mercados de suelo y los mecanismos de formación del precio constituyen pues una aproximación necesaria para comprender la diferenciación socioespacial y entender su materialidad a través de los precios inmobiliarios, que, a su turno, evidencian las desiguales posibilidades económicas de la pobladores: resultaría contraevidente clasificar como rico a quien habita en una vivienda o en un paisaje que reviste condiciones de precariedad. Las viviendas y entornos precarios están habitadas por residentes de escasos recursos (o capacidad de pago), mientras que las viviendas y entor- 
nos medios o lujosos acogen residentes de ingreso medio o alto, según sea el caso. La comprensión de los mecanismos que conforman la economía política de los espacios habitacionales en la ciudad permite desentrañar la forma como opera la generación y realización de la renta del suelo que reproduce la diferenciación de ambientes y entornos urbanos, y determina los patrones de vivienda que en ellos se construyen, dando cuenta además de las mínimas condiciones socioeconómicas de sus potenciales usufructuarios ${ }^{10}$.

\subsubsection{LA ZONIFICACIÓN CATASTRAL Y LOS PRECIOS INMOBILIARIOS PARA COMPRENDER LA RECOMPOSICIÓN RESIDENCIAL Y LA COMPLEJIDAD URBANA}

Como ya se ha sustentado, el inventario físico-jurídico-económico que administra y actualiza permanentemente el sistema catastral se constituye en un instrumento útil para captar y caracterizar la diferenciación socioespacial y para reflejar las condiciones socioeconómicas de los moradores de las distintas piezas que conforman el tejido urbano del Distrito Capital. Desde su misma concepción, los procesos catastrales están diseñados para dar cuenta de la diversidad de especificaciones, calidades y técnicas de construcción que se pueden percibir en las localidades capitalinas, además de ejercer la función de ‘termómetro' de la evolución del modelo de desarrollo urbano, de la dinámica inmobiliaria y del impacto de las transformaciones sociales y económicas en la estructuración y recomposición residencial bogotana.

Particularmente, la zonificación urbana (diseñada en los procesos catastrales) exhibe la separación de los diferentes grupos sociales en dominios espaciales concretos ${ }^{11}$, como lo evidencian la diversidad de investigaciones sobre la ciudad en América Latina, como Castells (1971), Roberts (1978), Santos (1978, 1978a, 1980, 1986, 1994), Singer (1979), Silveira (1999), Janoschka

10 Esta relación presenta excepciones, como sectores de hogares con baja capacidad de pago que se ven beneficiados por proyectos de renovación urbana específicos o familias que habitan en barrios que tradicionalmente tienen un nivel socioeconómico alto, pero que eventualmente van perdiendo capacidad de pago y no logran migrar a barrios más accesibles (fenómeno de pobreza oculta).

11 La diferenciación de ingresos, gastos, recursos (capital humano y social), de un lado, y la desigual participación en los beneficios de la inversión pública y privada, en las oportunidades y potencialidades, en el acceso a la riqueza, en las condiciones de vivienda y entorno, y la diferencial calidad de vida, del otro, evidencian la diferenciación de los grupos sociales que habitan y usan la ciudad y, en muchas ocasiones, de abismos y disparidades entre ellos. Ver sobre esto: Santos (1978), Santos et al. (1994), Silveira (1999) y Harvey (2008). 
(2002), Cabrales Barajas (2002), De Mattos (2002) y Sabatini (2004). Dicha zonificación y la diferenciación de valores (avalúos catastrales) entre las zonas urbanas permite traducir la desigualdad que caracteriza la ciudad no solo por sus características físicas, sino principalmente por el uso diferenciado (y las rentas diferenciales) al que sus suelos se destina ${ }^{12}$. Las rentas del suelo mencionadas anteriormente y su expresión en precios diferenciales (unitarios y totales, según si pertenecen o no al régimen de propiedad horizontal) en el mercado del suelo bogotano y de costos de las construcciones en él existentes representan la diferenciación que caracteriza a la ciudad en toda economía de mercado.

En tal zonificación, se manifiestan los efectos de los procesos acumulativos de capital y se percibe la especulación de precios inmobiliarios en un escenario de libre mercado, la natural diferenciación de ingreso disponible de los hogares, la pronunciada brecha económica y escasa movilidad social, que son factores convergentes y dan forma al citado fenómeno de reestructuración social en dominios espaciales concretos. La desigual distribución del ingreso y la capacidad de pago son un componente central para la estructuración del espacio socioeconómico bogotano.

Dentro de las claves para analizar el fenómeno de la recomposición residencial urbana, se erige la escasez de instrumentos regulatorios del mercado de vivienda capitalina, que tiene por sí misma impactos cruciales en el espacio social. La liberalización de alquileres y arrendamientos en Bogotá y el consiguiente restablecimiento de las rentas diferenciales ha llevado a que grandes sectores de la población deban trasladarse a zonas (por lo general periféricas) donde el precio del suelo es drásticamente menor, impera el desarrollo urbanístico ilegal y se desarrollan soluciones habitacionales por la vía de la autoconstrucción (Borja et al., 2003). En sentido contrario, la introducción de instrumentos eficaces que contengan la especulación rentística desatada en el mercado de vivienda podría eventualmente contener un fenómeno de

12 Eventualmente, el sistema catastral puede incluir información explícita sobre el territorio y la geografía humana y social, el transporte, la vialidad y la conectividad, información geográfico-ambiental e información socioeconómica y demográfica que permite establecer, mediante el análisis multidisciplinario, los patrones de uso (real y potencial), ocupación, intervención, sostenibilidad y potencialidad de las tierras de una determinada jurisdicción en sus diversas escalas. Con la información y la estructura de datos que maneja o incorpora, la infraestructura de un sistema catastral representa, por otra parte, una herramienta de planificación que puede usarse para atacar-o disfrazar-los problemas que plantea el desarrollo económico, la dinámica urbana, la erradicación de la pobreza, las políticas de suelo y el desarrollo sostenible. 
exclusión y segregación de población con menor capacidad de pago, expulsada por lo general de las áreas centrales con mejor dotación y equipamiento para las actividades residenciales.

Una de las explicaciones al fenómeno radica en que el precio de la vivienda (expresado con buen nivel de aproximación en el avalúo catastral) se forma de acuerdo con el mecanismo de la articulación de la renta urbana, descrito en la sección anterior. A través de este mecanismo, las viviendas localizadas en áreas centrales e inicialmente ocupadas por sectores de menos recursos pasan a ser ocupadas por sectores más ricos (o están desocupadas) y una parte de la población se encuentra forzada a mudarse hacia la periferia en viviendas unifamiliares de bajas especificaciones constructivas, ya que la producción capitalista de la vivienda no ofrece otras soluciones. Pequeños cambios en la distribución de ingreso se transforman en implicaciones importantes para la ocupación del territorio intraurbano.

Las dinámicas de ocupación, acceso y uso del suelo y diferenciación que se evidencian en el sistema urbano de conjunto parecen explicarse porque, entre las variables sintomáticas de la riqueza (o pobreza) de un territorio, se destacan tanto las formas de acceso a tierra habitable (ocupación e invasión, mercados informales e ilegales, urbanización espontánea, compra de lotes no servidos y autoconstrucción, urbanización planificada y ofertada por inversionistas y fondos de promoción de vivienda, mercado inmobiliario regular o especulativo, entre varias formas) como los precios por metro cuadrado que deben pagar los demandantes de suelo habitable.

De otra parte, la importancia de la vivienda propia dentro del ideario colectivo se convierte también en un factor de recomposiciones y transformaciones en la estructura del crecimiento físico de la ciudad de Bogotá, que es captada por la zonificación. En ese contexto, numerosas familias de ingresos medios usualmente residentes de las áreas centrales bajo la modalidad del alquiler se han visto motivadas a marcharse a la periferia de la ciudad (e, incluso, a los municipios metropolitanos), en donde la oferta de vivienda a costo más bajo les ofrece alternativas para sus posibilidades económicas, con el propósito de convertirse en propietarios. Conforme con Cuervo y otros, “(...) en el contexto sociocultural bogotano, el arrendamiento está frecuentemente identificado con dificultades de acceso a la vivienda, mientras que la propiedad es interpretada como el producto de recursos suficientes para acceder a condiciones aceptables de habitación" (Cuervo et al., 2000, p. 340). 
Estas son apenas algunas de las explicaciones que hay que establecer sobre las migraciones intraurbanas capitalinas y la recomposición residencial. A ellas se suman otro tipo de factores de mayor escala, como los instrumentos de planificación territorial (POT, plan de desarrollo, planes maestros, planes zonales, planes parciales, entre otros), que, a través de la normatividad urbanística, el modelo de crecimiento proyectado para la ciudad y los proyectos de inversión estratégica, estimulan o restringen el desarrollo, crecimiento y la consolidación del parque inmobiliario en distintas 'zonas' o sectores urbanos. Lo que se debe subrayar es que, sin importar su causa, magnitud o trayectoria espacial, esos cambios en la conformación del tejido socioeconómico residencial bogotano son modulados en gran medida a partir del mercado de suelo urbano y la capacidad de pago, siendo sus efectos percibidos a través de la zonificación catastral y los avalúos (precios) catastrales.

No obstante otras consideraciones y argumentos válidos sobre la recomposición urbana y la conformación de las áreas residenciales, en el siguiente apartado se elabora de forma general sobre algunas evidencias empíricas de esta reconfiguración urbana de la ciudad, así como del fenómeno de diferenciación-fragmentación-segregación socioeconómica en función de la lógica del mercado de suelo urbano y de la capacidad de pago de los moradores que acceden a los distintos productos inmobiliarios.

\subsubsection{LA RECOMPOSICIÓN SOCIOECONÓMICA DE LAS ÁREAS RESIDENCIALES BOGOTANAS Y LOS DIFERENCIALES DE CALIDAD DE VIDA URBANA: ALGUNAS EVIDENCIAS EMPÍRICAS}

Para efectos del análisis empírico, se propone en este apartado una aproximación a las migraciones intraurbanas y recomposición residencial urbana a través de dos elementos comparativos por localidades: a) las dinámicas demográficas en la ciudad, en las que se estudia el crecimiento (o decrecimiento) de la población en términos absolutos y las tasas de crecimiento anual acumulativo observadas para los períodos intercensales entre 1973 y 2013; y b) los diferenciales de calidad de vida urbana observados mediante el Índice de Calidad de Vida Urbana 2011. 
En términos generales, es posible evidenciar en la ciudad de Bogotá un crecimiento poblacional de gran relevancia para el período analizado, llegando a triplicar la población total registrada en el Censo de 1973 (ver figura 3.1). Específicamente, en lo que respecta a la movilidad residencial interna, para el período 1973-2013, es posible evidenciar un elevado crecimiento poblacional en las localidades ubicadas a lo largo del borde occidental, siendo la localidad de Suba la que más crecimiento registra desde 1973, y al año 2013 registra la mayor población de todas las localidades de la ciudad (1.120.342 habitantes).

La secuencia de mapas de la figura 3.2 nos permite apreciar la evolución de la dinámica demográfica por localidades en las últimas cuatro décadas y da cuenta de una tendencia al crecimiento poblacional de las áreas periféricas, de la mano con un vaciamiento progresivo de las localidades del centro ampliado. A grandes rasgos, esta tendencia puede reflejar el ya citado fenómeno de expulsión de los ciudadanos de menor poder adquisitivo hacia las regiones periféricas (esferas negras de mayor tamaño que en las áreas centrales), donde las condiciones habitacionales y territoriales revisten mayor precariedad, reservando las piezas urbanas más consolidadas a sectores minoritarios de la población. Mientras que al principio del período la población se concentraba principalmente en las localidades centrales (ver mapa año 1973, figura 3.2), progresivamente se experimenta una tendencia al vaciamiento de estas áreas centrales $^{13}$ (tasas de crecimiento en tonalidades amarillas y rojas) y a la concentración de la población en las áreas más periféricas, fundamentalmente en el borde occidental (tonalidades verdes). En este sentido, las localidades de Santa Fe, Los Mártires, Antonio Nariño y La Candelaria presentan tasas de crecimiento negativo durante prácticamente todo el período.

13 Para guía del lector, cabe destacar que, en los mapas, el tamaño de la esfera de color negro en cada localidad simboliza el tamaño de la población total, mientras que el color del relleno de los polígonos de las localidades representa las tasas de crecimiento observadas para cada período (tonalidades rojas y amarillas significan tasas negativas o pérdidas de población, mientras que las tonalidades verdes significan tasas positivas o crecimiento de la población). 


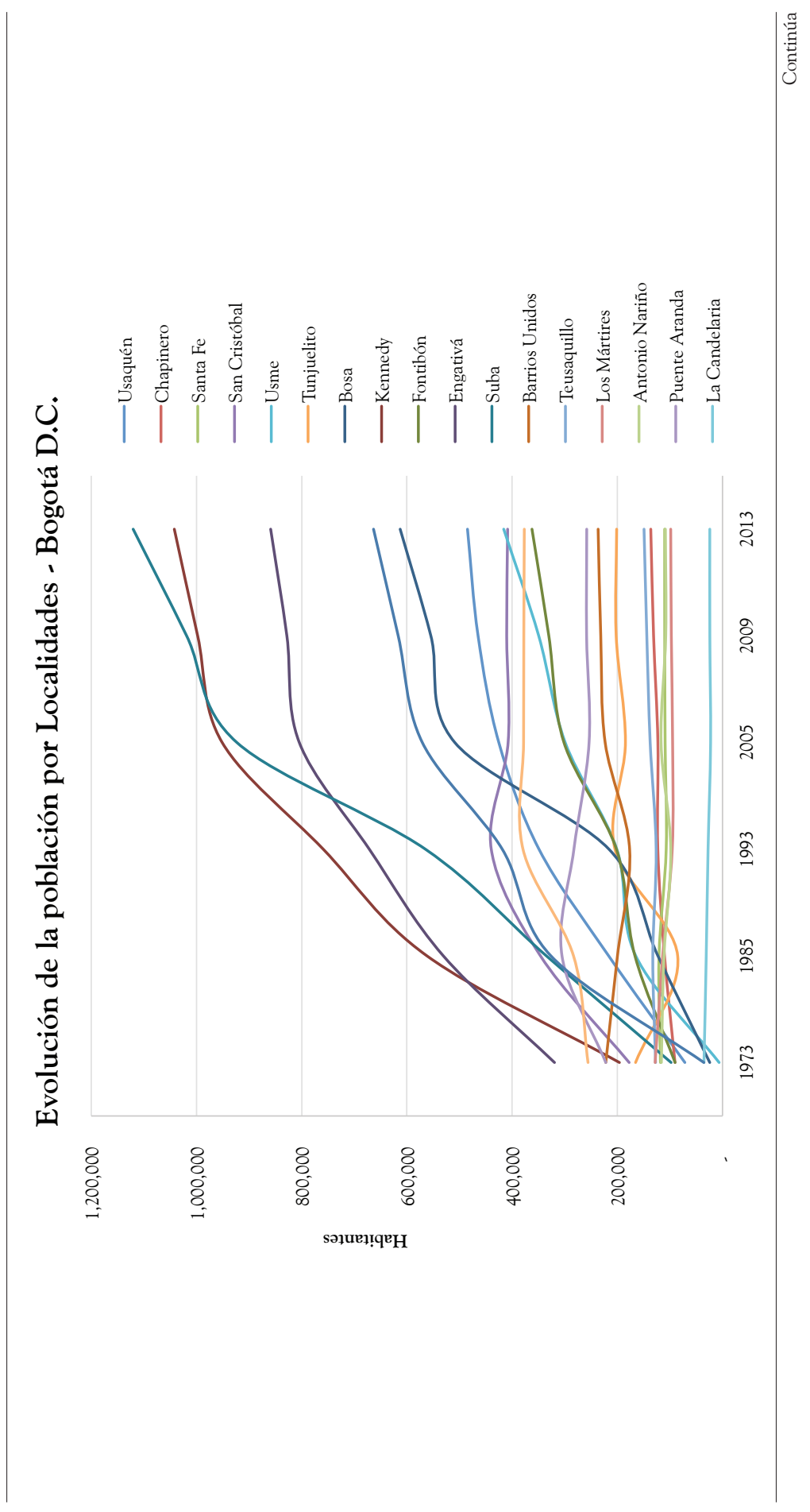




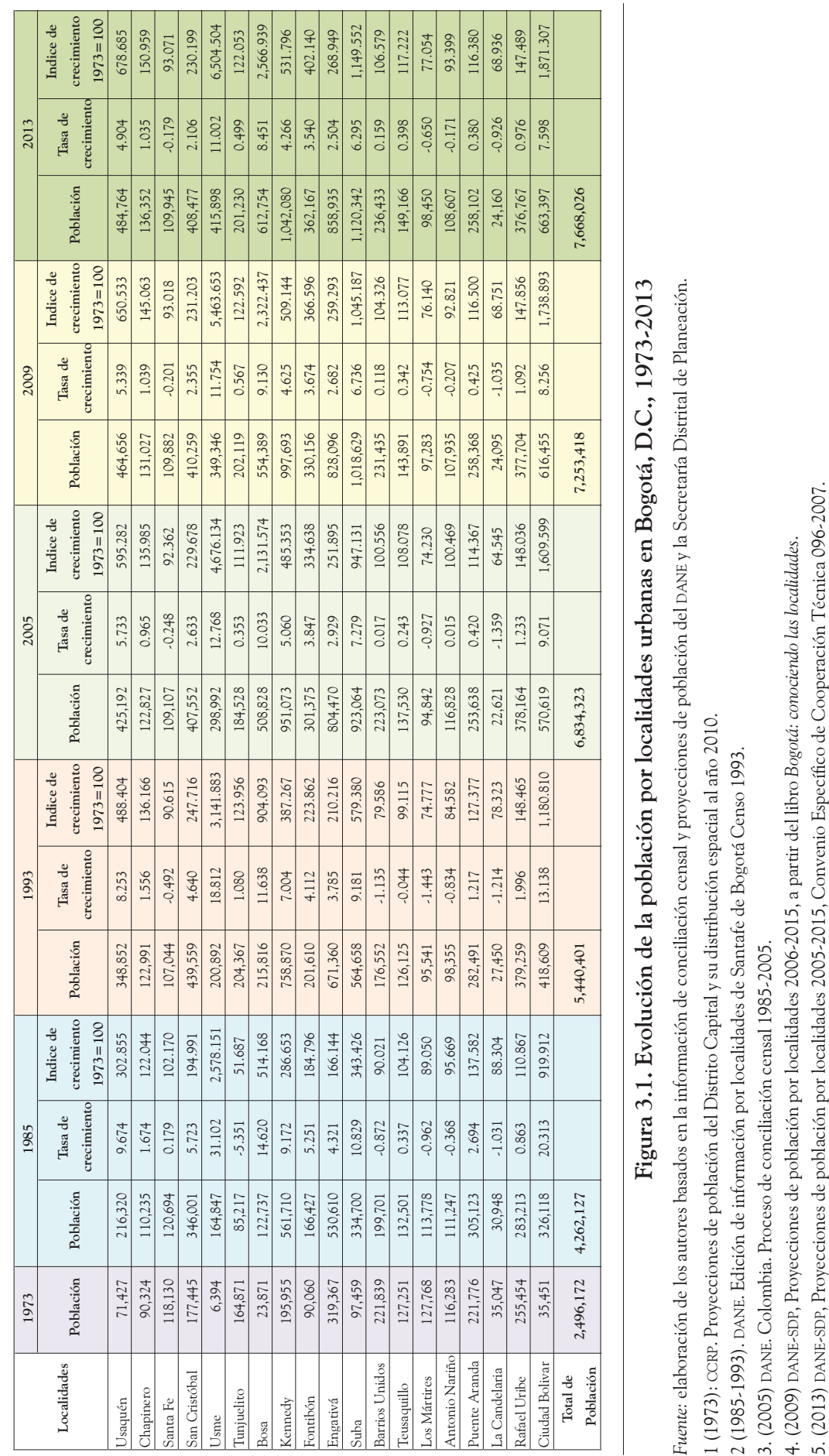



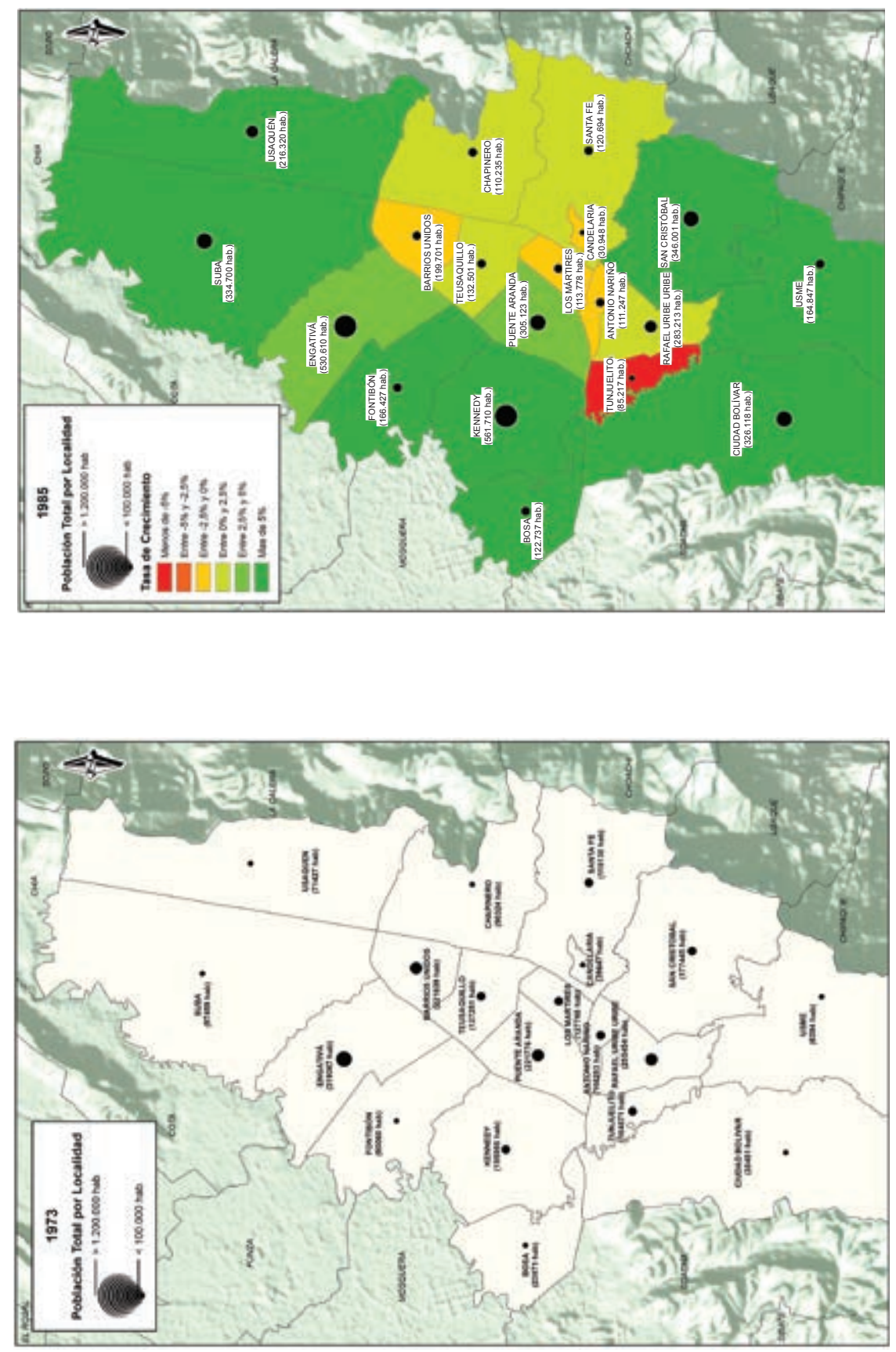

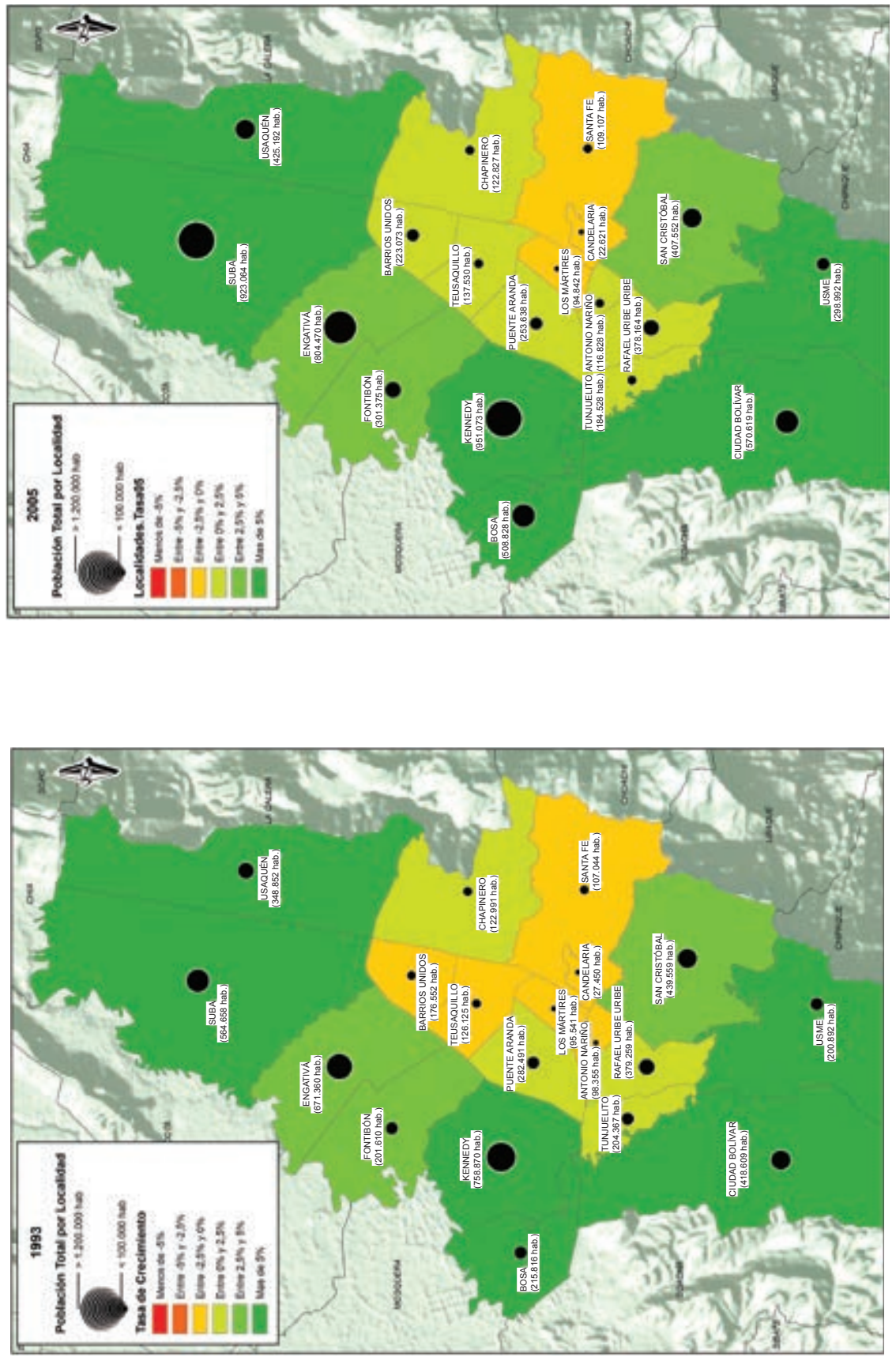

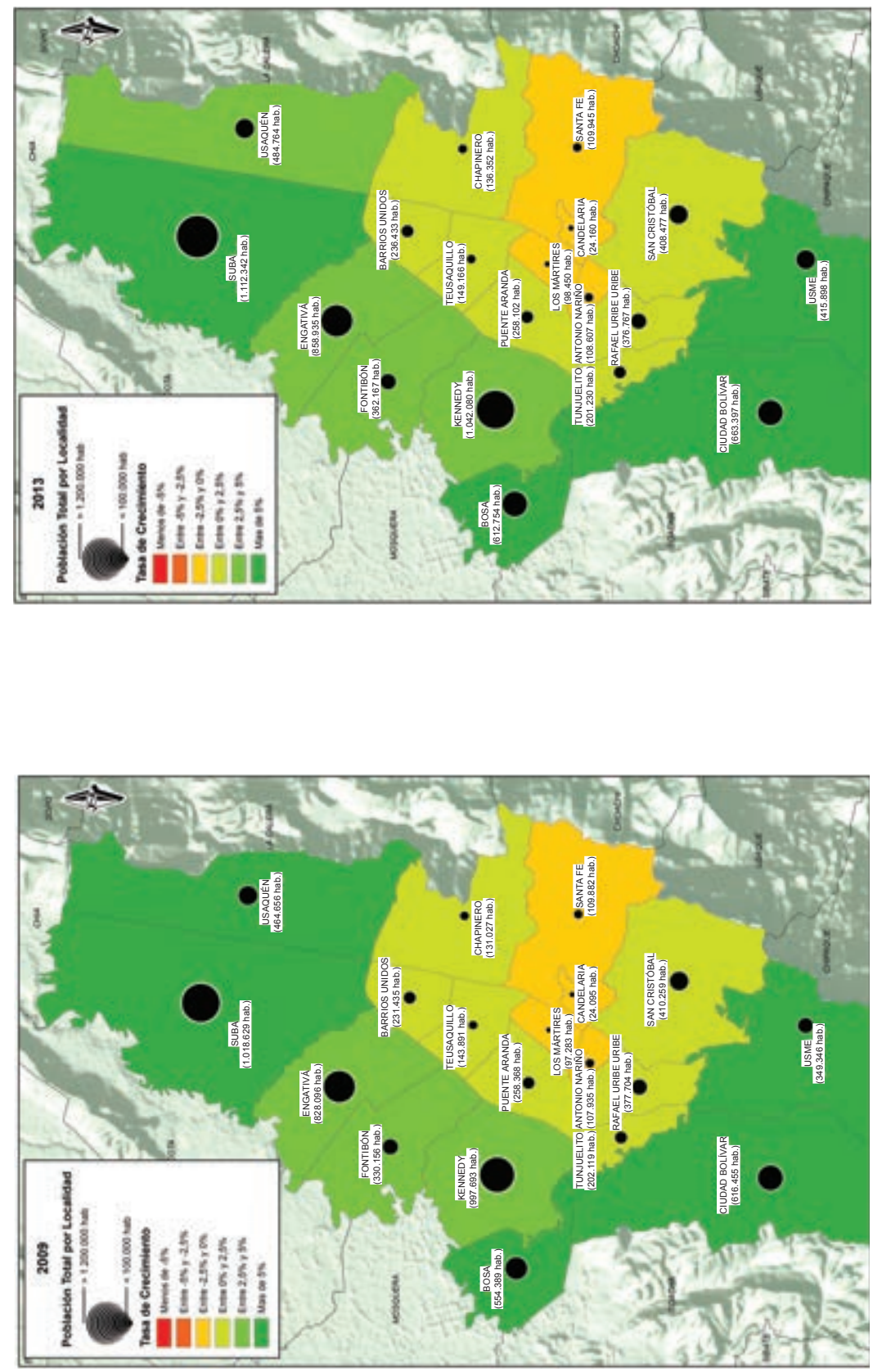

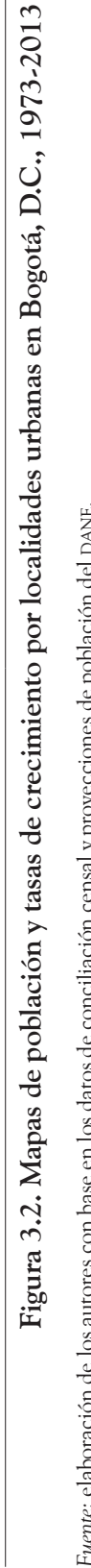


Como hipótesis para este comportamiento, se plantean tres factores. En primer término, los costos elevados que implica para gran parte de la población habitar en zonas de localización céntrica, gran oferta de transporte público y, en algunos casos, con catalogación patrimonial (La Candelaria y algunos barrios de Teusaquillo y Chapinero), debiendo, en muchas ocasiones, fundamentalmente a partir de la crisis de 1999, reducir gastos y, por lo tanto, asentarse en zonas más alejadas, precarias en conectividad y más económicas de la capital. En segundo lugar, la promoción de vivienda de interés social (VIS) e interés prioritario (VIP) de las últimas dos décadas en las localidades del borde occidental y en el sur causó que los residentes de las localidades centrales se marchasen a residir fuera del ahora denominado 'centro ampliado', para obtener una vivienda propia. Por último, la constitución de nuevas centralidades en diversos puntos de la ciudad, la difusión y crecimiento de las grandes superficies comerciales y el alto nivel de degradación urbanística de muchos de los barrios en las localidades de Santa Fe, Los Mártires, Antonio Nariño y Puente Aranda (esta última eminentemente industrial) fomentaron la suburbanización y la desconcentración de la población residente en el centro.

Paradójicamente con lo mencionado, son las localidades del centro las que poseen mayor número de equipamientos con respecto al tamaño de su población residente, la cual es considerablemente inferior en comparación con otras localidades del borde occidental y el eje sur de Bogotá. Así mismo, son las localidades de Teusaquillo y La Candelaria las que concentran el mayor número de bienes de interés cultural (Secretaría Distrital de Planeación, 2009).

En términos generales, parece existir una distribución de equipamientos por habitante que no corresponde con el crecimiento de población de las localidades observado en este período (y, por lo tanto, no estaría respondiendo a las demandas sociales) si se tiene en cuenta que "[...] La Candelaria figura con el mayor número de equipamientos por cada 10.000 habitantes (134), cifra que está muy por encima del promedio de la ciudad y de las localidades [...]. La localidad de Kennedy figura con el menor número de equipamientos por cada 10.000 habitantes (11), le siguen Suba (12), Bosa (13), Fontibón (14) y Tunjuelito (15)” (Secretaría Distrital de Planeación, 2009, p. 39). 


\begin{tabular}{|c|c|c|c|c|c|c|c|c|c|c|c|c|c|c|c|}
\hline 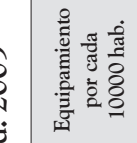 & $\stackrel{\infty}{\sim}$ & Ұ & $i n$ & $\approx$ & $\stackrel{亡}{\sim}$ & 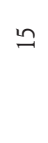 & $\approx$ & $=$ & \pm & $\simeq$ & $\simeq$ & $\stackrel{\sim}{\sim}$ & $\underset{m}{\infty}$ & શે & $\stackrel{\infty}{\longrightarrow}$ \\
\hline 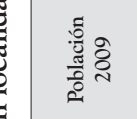 & $\begin{array}{l}\circ \\
\swarrow 0 \\
+் \\
+ \\
+\end{array}$ & $\begin{array}{l}\widetilde{\Xi} \\
\stackrel{\vec{\nabla}}{\sigma}\end{array}$ & $\begin{array}{l}\infty \\
\infty \\
\infty \\
O \\
0\end{array}$ & 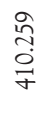 & 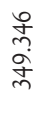 & $\begin{array}{l}\vec{D} \\
\stackrel{\vec{D}}{\tilde{d}}\end{array}$ & $\begin{array}{l}\infty \\
\infty \\
\stackrel{2}{*} \\
\text { in }\end{array}$ & 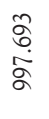 & $\begin{array}{l}\stackrel{0}{n} \\
\stackrel{0}{0} \\
\text { m }\end{array}$ & $\begin{array}{l}\stackrel{2}{ } \\
\text { oे } \\
\infty \\
\infty\end{array}$ & $\begin{array}{l}\stackrel{\text { ठे }}{\infty} \\
\stackrel{0}{0} \\
\stackrel{-}{-}\end{array}$ & 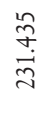 & $\begin{array}{l}\vec{\circ} \\
\stackrel{\dot{\Xi}}{\exists}\end{array}$ & 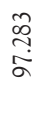 & $\begin{array}{l}\tilde{2} \\
\tilde{\alpha} \\
\tilde{\sigma}\end{array}$ \\
\hline 苟 & $\tilde{\infty}$ & $\vec{\infty}$ & 8 & $\frac{\Delta}{\sigma}$ & $\begin{array}{l}\text { lot } \\
\infty\end{array}$ & $\vec{D}$ & $\stackrel{\infty}{\perp}$ & $\stackrel{\varrho}{\leftrightarrows}$ & $\stackrel{\infty}{\stackrel{\infty}{\gamma}}$ & $\begin{array}{l}\widetilde{0} \\
\underset{\sim}{-}\end{array}$ & ڤ̊ & $\vec{f}$ & $\stackrel{\text { fr }}{n}$ & $\vec{\sim}$ & $\widetilde{\sigma}$ \\
\hline 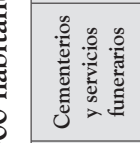 & in & $\sigma$ & $\simeq$ & $\sim$ & $n$ & + & in & + & $m$ & in & in & 0 & $a$ & + & $m$ \\
\hline 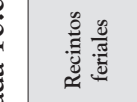 & & & - & & & & & & & & & - & - & & \\
\hline 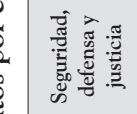 & $\simeq$ & $\cong$ & $\approx$ & $\approx$ & 으 & $=$ & $\approx$ & 2 & $\approx$ & 2 & $\stackrel{2}{2}$ & 0 & 으 & $\stackrel{\circ}{-}$ & $\sim$ \\
\hline 鹃 & 으 & 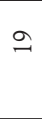 & $\approx$ & 0 & 0 & 0 & 0 & $\stackrel{\circ}{\sim}$ & \pm & $\stackrel{\circ}{\sim}$ & $\stackrel{\infty}{\sim}$ & $a$ & $\approx$ & + & $\sim$ \\
\hline 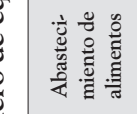 & in & $\sim$ & 0 & $m$ & $n$ & + & $\sim$ & 0 & in & $a$ & $m$ & $m$ & $\sim$ & $m$ & $\sim$ \\
\hline 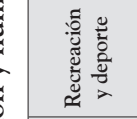 & $\simeq$ & $\sim$ & in & 0 & $n$ & - & $\sim$ & 6 & $\sigma$ & $\simeq$ & $\vec{\sim}$ & 으 & $m$ & - & - \\
\hline$\frac{8}{3}$ & $\stackrel{2}{\circ}$ & $q$ & $\vec{F}$ & 8 & $\approx$ & 우 & $F$ & ᄋి & $\stackrel{\infty}{\cap}$ & 先 & $\stackrel{\oslash}{=}$ & ৪ & $\approx$ & $\stackrel{\sim}{\sim}$ & $\tilde{\sim}$ \\
\hline$\frac{\mathbb{E}}{3}$ & $\mathscr{F}$ & $\stackrel{ \pm}{ }$ & oิ & $\beta$ & $\tilde{6}$ & 으 & $\stackrel{q}{f}$ & $\tilde{\infty}$ & $\stackrel{n}{n}$ & F & $\stackrel{\infty}{\sim}$ & 으 & $\stackrel{\infty}{+}$ & 으 & $\simeq$ \\
\hline 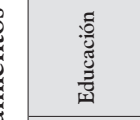 & $\approx$ & $\stackrel{゚}{\beth}$ & $\stackrel{ }{=}$ & $\underset{\beth}{ \pm}$ & $\stackrel{ }{\exists}$ & ธิ & $\stackrel{\infty}{\simeq}$ & $\underset{\sim}{\mathbb{N}}$ & $\tilde{\sigma}$ & శ్ర & $\stackrel{\text { }}{\vec{f}}$ & $\approx$ & $\stackrel{\text { I }}{ }$ & t & $\approx$ \\
\hline 丞 & $\stackrel{\infty}{m}$ & 으 & $\Xi$ & $\stackrel{2}{\sim}$ & $\stackrel{\infty}{\sim}$ & 2 & $\tilde{\sim}$ & $\approx$ & $\simeq$ & $\stackrel{\nabla}{ }$ & $\vec{\sim}$ & \pm & $\simeq$ & $\stackrel{\Xi}{\sim}$ & $\infty$ \\
\hline 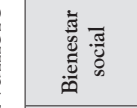 & 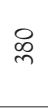 & $\tilde{\approx}$ & $\underset{\sim}{\sim}$ & in & $\stackrel{\infty}{\circ}$ & $\hat{\varrho}$ & 品 & t্ & $\underline{6}$ & $\overrightarrow{\sigma o}$ & $\widetilde{\widetilde{n}}$ & $\stackrel{?}{\text { ? }}$ & 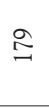 & $\stackrel{\oslash}{\nexists}$ & $\tilde{n}$ \\
\hline 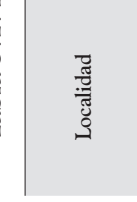 & 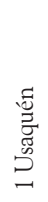 & 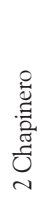 & 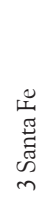 & 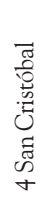 & 苟 & 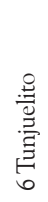 & 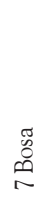 & 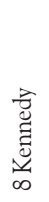 & 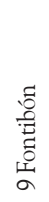 & 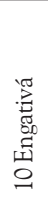 & $\begin{array}{l}\frac{\pi}{3} \\
\tilde{B} \\
=\end{array}$ & 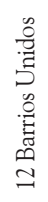 & 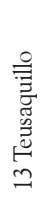 & 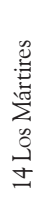 & 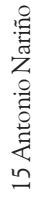 \\
\hline
\end{tabular}




\begin{tabular}{|c|c|c|c|c|c|c|c|c|}
\hline 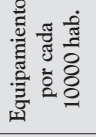 & $\stackrel{\infty}{-}$ & $\stackrel{ \pm}{=}$ & $\approx$ & 이 & $\vec{m}$ & & 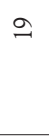 & \\
\hline 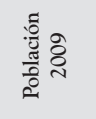 & $\begin{array}{l}\infty \\
\infty \\
\infty \\
\infty \\
\vdots \\
\sim\end{array}$ & 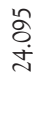 & 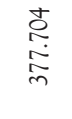 & $\begin{array}{l}\frac{2}{2} \\
\text { fo } \\
b \\
\stackrel{0}{0}\end{array}$ & 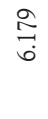 & & 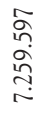 & \\
\hline 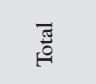 & 角 & $\approx$ & $\stackrel{\infty}{\infty}$ & 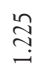 & $\stackrel{-}{9}$ & ळे & $\begin{array}{l}\stackrel{\Xi}{ } \\
\stackrel{\sim}{\beth}\end{array}$ & 8 \\
\hline 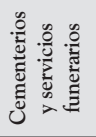 & - & & $m$ & + & $m$ & & $\infty$ & $\begin{array}{l}0 \\
0\end{array}$ \\
\hline 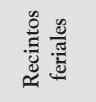 & & & & & & & $m$ & ठ̃ \\
\hline 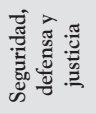 & \pm & $\simeq$ & 으 & $\Xi$ & & - & ర్లి & $\Rightarrow$ \\
\hline 离 & $=$ & $\stackrel{\infty}{\sim}$ & $\infty$ & $\sim$ & & $\sim$ & $\stackrel{\infty}{\sim}$ & $\stackrel{\infty}{\rightarrow}$ \\
\hline 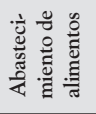 & + & - & $\sim$ & $\sigma$ & & $\sim$ & $\approx$ & $\tilde{o}^{2}$ \\
\hline 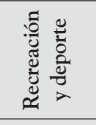 & in & & 0 & $m$ & & & $\stackrel{\infty}{\stackrel{c}{2}}$ & $\begin{array}{l}\infty \\
0 \\
0\end{array}$ \\
\hline$\frac{\stackrel{̊}{J}}{J}$ & in & $\stackrel{0}{\circ}$ & $\approx$ & $\stackrel{ \pm}{ \pm}$ & $\sim$ & $\stackrel{\sim}{\sim}$ & 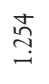 & $\widetilde{a}$ \\
\hline$\frac{\tilde{E}}{\Xi}$ & $\approx$ & 우 & $\stackrel{\infty}{\infty}$ & $\infty$ & $n$ & $\sim$ & $\begin{array}{l}\infty \\
\infty \\
\infty\end{array}$ & $n^{2}$ \\
\hline 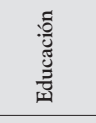 & $\stackrel{\infty}{\curvearrowleft}$ & ऽ̊ & $\stackrel{\cong}{\infty}$ & $\underset{\beth}{ \pm}$ & $\sigma$ & - & $\stackrel{\bar{n}}{\bar{m}}$ & $\begin{array}{l}\stackrel{\infty}{\sim} \\
\stackrel{2}{\sim}\end{array}$ \\
\hline$\frac{\vec{Z}}{\tilde{m}}$ & $\stackrel{n}{\simeq}$ & $\infty$ & $\vec{\sim}$ & $\tilde{m}$ & $m$ & & $\stackrel{\text { }}{\text { r }}$ & ते \\
\hline 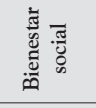 & $\stackrel{\infty}{\circ}$ & $\stackrel{\varrho}{=}$ & 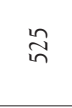 & $\underset{\infty}{\widetilde{\infty}}$ & & & 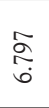 & के \\
\hline 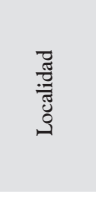 & 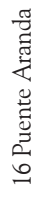 & 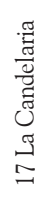 & 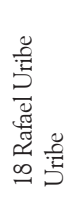 & 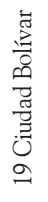 & 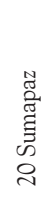 & 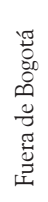 & 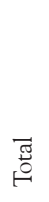 & $\partial^{\circ}$ \\
\hline
\end{tabular}


En cuanto a las localidades del eje sur (Usme, Ciudad Bolívar, Rafael Uribe y San Cristóbal), la acogida de nuevos moradores provenientes de otras regiones del país en calidad, por ejemplo, de desplazados por el conflicto armado ha hecho que en estas últimas cuatro décadas esta zona de la ciudad evidencie tasas de crecimiento muy elevadas (mayores al $5 \%$ anual y, en algunos casos, por encima del 30\% -mapas de la figura 3.2-), desde 1973. Teniendo en cuenta que "la localidad de Ciudad Bolívar registra el mayor número de equipamientos de bienestar social con 823, le sigue Engativá con 681 y Usme con 598" (Secretaría Distrital de Planeación, 2009, p. 48), parece intuitivo deducir que el crecimiento poblacional evidenciado en estas zonas está vinculado a algunos de los sectores sociales más vulnerables de la ciudad, con mayores necesidades de asistencia y altos niveles de pobreza. Particularmente, la localidad de Usme es la que presenta las tasas de crecimiento poblacional más elevadas durante todo el período, hecho que llama la atención si se tiene en cuenta que constituye la zona urbana con la mayor incidencia del sistema de áreas protegidas de la ciudad, de conformidad con lo establecido en el Plan de Ordenamiento Territorial de Bogotá.

Los patrones culturales han llevado a que las personas opten (quienes pueden hacerlo) por la propiedad como forma mayoritaria de tenencia de la vivienda, lo cual implica en muchos casos desplazamientos a zonas donde este 'sueño' esté al alcance de las posibilidades económicas. El comportamiento poblacional intraurbano parecería estar cuestionando la capacidad de la ciudad de promover una apropiación y derecho al uso (al menos en términos residenciales) de las zonas consolidadas en espacio capitalino, marcando una pauta segregante, inequitativa y excluyente de la ciudad. Así mismo, podría estar hablando de las deficiencias en la planificación del crecimiento en las zonas periféricas, carentes por lo general de servicios urbanos y recursos para una verdadera calidad de vida urbana.

Complementariamente a este último concepto, en esa misma dirección, se destacan algunos de los resultados del estudio Calidad de vida urbana y capacidad de pago de los hogares bogotanos 2011 (CID, 2012), en el que se construyó un indicador de calidad de vida urbana (ICVU) a partir de un conjunto de doce dimensiones seleccionadas: salud y alimentación, condiciones de la vivienda, calidad ambiental, equipamientos y dotaciones urbanas, movilidad, seguridad ciudadana, trabajo, educación, ocio y recreación, solidaridad y asociación, no discriminación y capacidad de pago. 
Los resultados del estudio arrojan que, en primer lugar, hay que mencionar que el índice promedio de la calidad de vida urbana llega al 0,61 (en escala de 0 a 1 , donde 0 es una baja calidad de vida urbana y 1 representa una alta calidad de vida urbana), evidenciando limitaciones en cuanto a capacidades y libertades. En el informe, se señalan los promedios calculados para cada dimensión, teniendo a la calidad ambiental $(0,5285)$, la seguridad ciudadana $(0,5732)$, el ocio y la recreación $(0,3271)$, la no discriminación $(0,5091)$ y la capacidad de pago $(0,0269)$ como las dimensiones que presentan promedios más bajos.

En las conclusiones del estudio, se observa una profunda diferenciación y desigualdad de los hogares a nivel socioeconómico y espacial, teniendo en cuenta la información suministrada a partir de los estratos socioeconómicos y a nivel de las localidades:

(...) al parecer en Bogotá existen dos ciudades: la que conforman los estratos 1,2 y 3 ; y la opulenta, que componen los estratos 4,5 y 6 . Esta segmentación de la ciudad en términos de la calidad de vida de los hogares bogotanos exige un replanteamiento de las políticas públicas. Es urgente que las condiciones de vida urbana para los estratos 1, 2 y 3 mejoren más rápidamente que la de los estratos 4,5 y 6, pues de lo contrario el llamado efecto túnel se puede disipar y generar serias tensiones entre la población de las dos ciudades, deteriorando otros indicadores como los de convivencia y seguridad (CID, 2012, p. 133).

Cuando se observa el comportamiento de las distintas dimensiones del índice de calidad de vida urbana (ICVU) en las localidades, resulta evidente una notable diferenciación entre los hogares analizados y la existencia de tres grupos de localidades según la calidad de vida urbana que ofrecen a sus moradores:

El conjunto compuesto por Teusaquillo, Usaquén, Fontibón y Chapinero, con índices que están por encima de 0,64; el grupo más numeroso que incluye a Barrios Unidos, Puente Aranda, Engativá, Antonio Nariño, Suba y Tunjuelito, en los cuales el índice oscila entre 0,61 y 0,64; y, finalmente, el grupo de la mayoría: La Candelaria, Kennedy, 
Santa Fe, Los Mártires, Rafael Uribe Uribe, Bosa, Ciudad Bolívar, San Cristóbal y Usme, en donde el ICVU está por debajo del índice de la ciudad $(0,61)$ (CID, 2012, p. 130).

Estos diferenciales de calidad de vida en el interior de la ciudad expresan una inequitativa distribución de los factores de desarrollo urbano y un modelo de crecimiento basado en la liberalización del mercado inmobiliario, que lleva a una recomposición urbana en función de la diferencial capacidad de pago de los hogares. El hecho de que, en 2013, localidades del borde sur y occidental, como San Cristóbal, Rafael Uribe Uribe, Usme, Ciudad Bolívar, Bosa, Kennedy, experimenten tasas de crecimiento significativamente altas y, a la vez, detenten los índices más bajos de calidad de vida urbana (figura 3.3) es una evidencia de una segmentación socioeconómica urbana instrumentalizada a través de la capacidad de pago de los hogares, que, en el contexto actual, tiende a profundizarse, reflejando la diferenciación de las condiciones materiales e inmateriales en las que viven (o en las que pueden vivir) los habitantes de la ciudad. Al respecto, el estudio Segregación socioeconómica en el espacio urbano de Bogotá D.C. concluyó: "La desigualdad en el ingreso es la principal causa de la segregación. El alto ingreso de algunos hogares les permite autosegregarse y vivir donde y como quieren. El bajo ingreso de otros hogares les obliga a vivir donde y como puedan. Existen, entonces, poderosas fuerzas sociales y económicas que llevan a la separación espacial entre hogares ricos y pobres" (Secretaría Distrital de Planeación, 2013, p. 83).

\subsection{Una propuesta para el cálculo del avalúo catastral sin efecto del estrato socioeconómico}

Debido a que el cálculo del avalúo catastral toma en cuenta el estrato socioeconómico, es necesario estudiar y estimar su efecto en dicho proceso. El uso de la información catastral como eventual herramienta en la propuesta de una nueva metodología de estratificación de inmuebles tiene un impacto no solo en la conceptualización de un 'estrato socioeconómico', que lleva a la necesidad de evitar una alteración acumulativa y cíclica al usar el estrato actual dentro del respectivo cálculo catastral. 

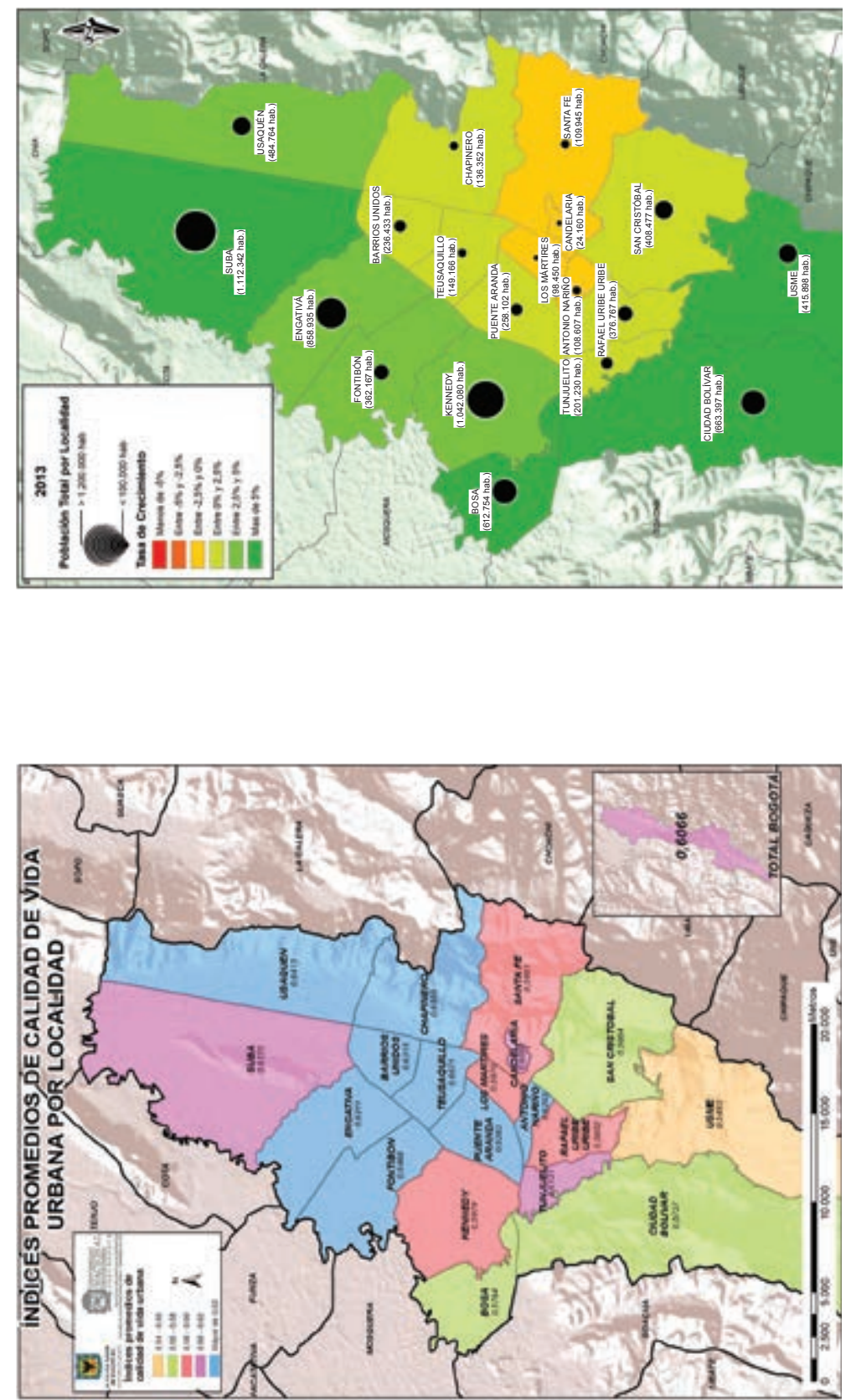
En la determinación del efecto del estrato socioeconómico sobre el avalúo, se presentan dos tipos de fuentes de afectación que, de forma implícita o explícita, influyen en el comportamiento de la variable: el primero puede ocurrir a partir de preconcepciones sobre la definición de estrato por parte de los avaluadores en el proceso valuatorio del inmueble, que lleve un sesgo difícilmente medible y para el cual su depuración debe ser lograda a través de una adecuada capacitación por parte de la UAECD como ente regulatorio del debido proceso. En segundo lugar, es la incorporación explícita (y cuantificable) del estrato en los modelos econométricos para el cálculo de valores unitarios-comerciales de construcción y fundamentalmente en lo que respecta a los predios con uso residencial (Res. 1585/11, anexo 2 -UAECD, 2011-).

Estas últimas secciones buscan proponer una medición del valor unitario integral de los inmuebles, como referente principal para determinar eventuales subsidios en tarifas de servicios públicos domiciliarios, de manera que no tenga en cuenta el estrato socioeconómico vigente en el cálculo del avalúo catastral.

\subsubsection{CUANTIFICACIÓN DEL EFECTO DEL ESTRATO SOCIOECONÓMICO EN EL CÁLCULO DEL AVALÚO CATASTRAL Y FORMULACIÓN DE UN 'VALOR UNITARIO INTEGRAL' DEL AVALÚO}

Una limitación en el estudio del avalúo es la comparabilidad en términos absolutos de un predio respecto a otro sin tener en cuenta las áreas de cada uno de ellos. De esta forma, la UAECD introduce el concepto de valor de construcción (VINT). Las diferencias en los tamaños de terreno entre los predios de propiedad horizontal ( $\mathrm{PH}$ ) y los predios no PH no permiten una comparación directa entre ellos, por lo que es necesario construir una variable que incorpore los valores de los predios controlando tanto el tamaño del área construida como la del terreno asignado a cada uno.

Se propone así una variable definida como valor único integral del avalúo, de modo que se facilite la determinación de la relación entre la información catastral y las condiciones socioeconómicas de los hogares (capítulo 4), la implementación de nuevos modelos de estratificación socioeconómica (capítulo 5) o esquemas alternativos de tarifas de servicios públicos domiciliarios (capítulo 7) basados en esta información. Estas razones apuntan a comple- 
mentariamente estudiar el efecto del estrato socioeconómico sobre el avalúo y el valor unitario que de este se deriva ${ }^{14}$.

El valor unitario integral del avalúo (VUI) se define de la siguiente manera ${ }^{15}$ :

Valor unitario integral $= \begin{cases}\frac{\text { Avalúo }}{\text { área construida }} & \text { si es PH } \\ \text { Valor M2 Terreno }+ \text { Valor M2ConstPonderado } & \text { si es NPH }\end{cases}$

Donde ValorM2ConstPonderado corresponde a un promedio del valor de la construcción de las unidades con uso residencial ponderado por el área de construcción respectiva a cada unidad.

\subsubsection{Estimación de modelos econométricos}

La UAECD (2011) define el cálculo del valor de construcción de cada inmueble por tipo de régimen de propiedad horizontal (propiedad horizontal - $\mathrm{PH}-\mathrm{y}$ no propiedad horizontal -NPH-) y grupos de estrato, a partir de un conjunto de variables de diferente naturaleza, como el estado del inmueble, su entorno urbanístico y ubicación georreferenciada, estableciendo cuatro modelos diferenciados: para los estratos 1, 2 y 3; otro para los estratos 4, 5 y 6, ambos según su clasificación como PH o NPH.

El valor del metro cuadrado de construcción o valor unitario de construcción (VM2Const, denominado valor integral para el caso de PH) de inmuebles con un uso residencial se calcula a partir de un muestreo de predios representativo a nivel de la zona homogénea geoeconómica $(\mathrm{ZHG})^{16}$, a través de dos pasos: primero, la estimación de modelos lineales generalizados $(\mathrm{MLG})^{17}$,

14 Esto debido a que el avalúo es afectado directamente por el valor unitario de terreno, el cual puede incorporar el efecto del estrato socioeconómico que se origina de forma explícita en el cálculo del valor unitario de construcción. En este sentido, es evidente que esta variable no debe ser un insumo del cálculo del avalúo, para no generar circularidad.

15 En términos del régimen de propiedad horizontal y particularmente en caso de predios clasificados como NPH, deben considerarse únicamente aquellas unidades que tienen un uso residencial.

16 Se encuentra en unidades de valor comercial debido a que el trabajo de campo es llevado a cabo por parte de los avaluadores, que, de acuerdo con su pericia técnica, determinan el valor según una serie de consideraciones, como el estado del inmueble, su puntaje catastral y características del entorno urbanístico.

17 Conjunto de variables que relacionan el valor de metro cuadrado de terreno: puntaje catastral, edad del inmueble, área de construcción para los diferentes usos, variables de la superficie del terreno 
con la muestra de predios base y su respectiva predicción sobre predios sin VM2Const, y, segundo, un decremento porcentual en los valores de suelo y construcción determinado por el Consejo Superior de Política Fiscal (Confis). El avalúo catastral resulta de la sumatoria de los dos valores a nivel predial: el valor unitario de construcción y de terreno.

Con base en la muestra de puntos catastrales realizada para la vigencia 2013, se reproducen los modelos vigencia 2012 plasmada en el anexo 2 de la Resolución 1585 de 2011 (UAECD, 2011) ${ }^{18}$. Se replican, entonces, los cuatro modelos estándar descritos (modelo estrato bajo para PH y NPH, y modelos para estrato alto para PH y NPH) y se estiman dos modelos básicos general sin estrato socioeconómico (PH y NPH). En ambos casos (con y sin estrato), el ejercicio resulta en un cálculo de valor unitario de terreno estimado. Los resultados de los modelos se presentan en las tablas A5.1 y A5.2 del anexo 5 (sección 1) ${ }^{19}$.

Los pasos técnicos que se siguieron para la definición del avalúo alternativo (valor unitario integral) se presentan a continuación:

- Se consolidaron las variables que componen el valor unitario de construcción para PH y NPH, sin estrato socioeconómico, listadas en el anexo técnico de la Resolución de la UAECD 1585 de 2011.

- Se ajustan los modelos, a través de una revisión progresiva de las variables, y se escogen aquellas que son significativas en la explicación del VM2Const.

- Se analiza el ajuste, valores atípicos, valores influenciales y comportamiento general del modelo frente a los errores que arroja su estimación.

(topografía), estado e influencia de las vías, tipo de tratamiento urbanístico según el POT, valores relacionados con la georreferenciación del predio, sectorización dada por el sector catastral del inmueble y estrato socioeconómico (para el caso del conjunto de modelos propuesto, no se encuentra incluida esta última variable).

18 Se le llama reproducción de modelos econométricos debido a dos limitaciones: la primera está ligada a las limitaciones de información por cuestiones de completitud en la muestra vigencia 2012. La segunda está dada por la 'depuración' de modelos que realiza la UAECD en el proceso de retroalimentación que surgen de expertos en el comportamiento del mercado inmobiliario. Por lo tanto, dichos modelos no se enmarcan dentro de los óptimos en términos estadísticos (significancia, completitud o redundancia).

19 El proceso estadístico fue efectuado por medio del software estadístico R (R Core Team, 2013), bajo los criterios que permite la rutina glm, se ajustaron los diferentes modelos apoyándonos particularmente en los MLG tipo gamma a través del enlace logarítmico. 
- Se ajusta el modelo inicial de tal forma que el rango de variación de los residuales tipo desvío que se asocian al modelo sean inferiores a 2,5.

Es útil resaltar que, en la etapa inicial de estimación de modelos de avalúo, con y sin estrato, se evidenció un impacto explícito del estrato principalmente sobre el valor del metro cuadrado construido del 5,28\%, medido a través de la estadística de ajuste $R^{2}$ (coeficiente de determinación del modelo de regresión), la cual compara la similitud entre los valores originales de las variables y la aproximación que predicen los modelos con y sin estrato. El efecto pasa a ser menor en el cálculo del avalúo catastral y del valor unitario integral, ya que estos tienen en cuenta el valor unitario del terreno, el cual entra a tomar un peso significativo en las respectivas estimaciones.

Teniendo en cuenta estas consideraciones y bajo el modelo de regresión gamma con enlace exponencial, se estiman los parámetros (tabla 3.2), siendo la exponencial del estimador la vía de interpretación de los coeficientes estimados; así los $\$ 88.025$ y $\$ 221.506,88$ respectivamente para NPH y PH relacionados a sus interceptos son el punto de partida de los valores unitarios de construcción. Para el modelo NPH, por cada aumento de $\$ 100.000$ del valor de metro cuadrado de terreno, se espera un incremento del $2,28 \%$ en el valor integral del avalúo; de la misma forma, por cada aumento de 10 puntos en el puntaje catastral, el valor integral se incrementará en un 18,03\%. Análogamente, para el nuevo modelo PH, con un cambio de $\$ 100.000$ en el valor de metro cuadrado de terreno, se espera un incremento del 3,4\% del valor integral del avalúo propuesto.

Tabla 3.2.A. Estimación de coeficientes para el modelo propuesto - NPH

\begin{tabular}{l|r|r|l|r|r}
\hline & Estimador & $\begin{array}{r}\text { Exponencial } \\
\text { del estimador }\end{array}$ & & Estimador & $\begin{array}{c}\text { Exponencial } \\
\text { del estimador }\end{array}$ \\
\hline Intercepto & 11,39 & 88025,43 & Estado_vía2 & 0,05 & 1,06 \\
\hline Act_económica_121312 & $-0,04$ & 0,96 & Estado_vía3 & 0,06 & 1,06 \\
\hline Act_económica_121314 & 0,23 & 1,26 & Estado_vía4 & 0,13 & 1,13 \\
\hline Act_económica_121322 & 0,02 & 1,02 & Inf_vía1 & 0,12 & 1,12 \\
\hline Cent_cll_72_cll_100 & $-0,09$ & 0,91 & Inf_vía2 & 0,05 & 1,05 \\
\hline Cent_Ferias & $-0,15$ & 0,86 & Inf_vía3 & 0,07 & 1,08 \\
\hline
\end{tabular}




\begin{tabular}{l|r|r|l|r|r}
\hline & Estimador & $\begin{array}{r}\text { Exponencial } \\
\text { del estimador }\end{array}$ & Estimador & $\begin{array}{c}\text { Exponencial } \\
\text { del estimador }\end{array}$ \\
\hline Cent_Font_Aerop_Eng & $-0,04$ & 0,96 & Puntaje & 0,02 & 1,02 \\
\hline Cent_Prado_Verang & $-0,09$ & 0,92 & Relación_área & 0,04 & 1,04 \\
\hline Cent_Siete_Agosto & $-0,13$ & 0,88 & Topografía2 & $-0,04$ & 0,96 \\
\hline Cent_Toberín_La_Paz & $-0,08$ & 0,93 & Topografía3 & $-0,04$ & 0,96 \\
\hline Coordenada_x & 0,0000051 & 1,00 & Uso_002 & 0,07 & 1,07 \\
\hline Coordenada_y & 0,0000016 & 1,00 & Valor_m2_terreno & 0,0000002 & 1,00 \\
\hline Edad & $-0,01$ & 0,99 & & &
\end{tabular}

Fuente: elaboración de los autores a partir de la base catastral 2012 y UAECD (2011). La definición de cada variable se encuentra en el anexo 5 .

Tabla 3.2.B. Estimación de coeficientes para el modelo propuesto $\mathrm{PH}$

\begin{tabular}{l|r|r|l|r|r}
\hline & Estimador & $\begin{array}{r}\text { Exponencial } \\
\text { del estimador }\end{array}$ & Estimador & $\begin{array}{c}\text { Exponencial } \\
\text { del estimador }\end{array}$ \\
\hline Intercepto & 12,31 & 221506,88 & Puntaje & 0,01 & 1,01 \\
\hline Área_act22 & $-0,03$ & 0,98 & Sectores_ORP1 & $-0,29$ & 0,75 \\
\hline Área_act23 & $-0,09$ & 0,91 & Ter_MAY3RP2 & $-0,35$ & 0,70 \\
\hline Área_act41 & $-0,21$ & 0,81 & Topografía2 & $-0,11$ & 0,90 \\
\hline Área_act45 & $-0,19$ & 0,82 & Topografía3 & $-0,12$ & 0,88 \\
\hline Área_act46 & $-0,20$ & 0,82 & Tratamiento11 & 0,05 & 1,05 \\
\hline Área_terreno_Porc & 0,0007 & 1,00 & Tratamiento21 & 0,06 & 1,06 \\
\hline Área_uso & $-0,0002$ & 1,00 & Tratamiento22 & 0,13 & 1,14 \\
\hline Clase_vía2 & $-0,27$ & 0,77 & Tratamiento23 & 0,05 & 1,05 \\
\hline Clase_vía3 & $-0,15$ & 0,86 & Tratamiento8 & 0,002 & 1,02 \\
\hline Clase_vía4 & $-0,09$ & 0,91 & Uso_037 & 0,08 & 1,09 \\
\hline Coordenada_x & 0,00001 & 1,00 & Uso_038 & Valor_m2_terreno & 1,12 \\
\hline Edad_ & $-0,01$ & 0,99 & 1,00 \\
\hline
\end{tabular}

Fuente: elaboración de los autores a partir de la base catastral 2012 y UAECD (2011). La definición de cada variable se encuentra en el anexo 5 . 
Siguiendo la metodología de cálculo del avalúo (sección 3.2.1), se estima el VM2Const para 1.548.740 inmuebles clasificados como residenciales, tanto para aquellos clasificados como PH como para NPH. Este valor identifica entonces un valor unitario de construcción sin efecto de estrato y el cual permite calcular un nuevo avalúo comercial a través de la adición del valor de terreno. El valor final guarda la misma ausencia de comparación del avalúo según la metodología actual, por lo tanto, apoyando el resultado en la fórmula del vUI, se puede calcular un nuevo valor unitario integral que elimine explícitamente variables relacionadas con el modelo de estratificación actual. La forma distribucional del vUI propuesto es presentada en la figura 3.4, la cual deja entrever que existe una fuerte agrupación comprendida entre los valores de $\$ 798.517$ y $\$ 1.888 .958$ (50\% de la información), tomando como valor medio el $\$ 1.430 .621$.

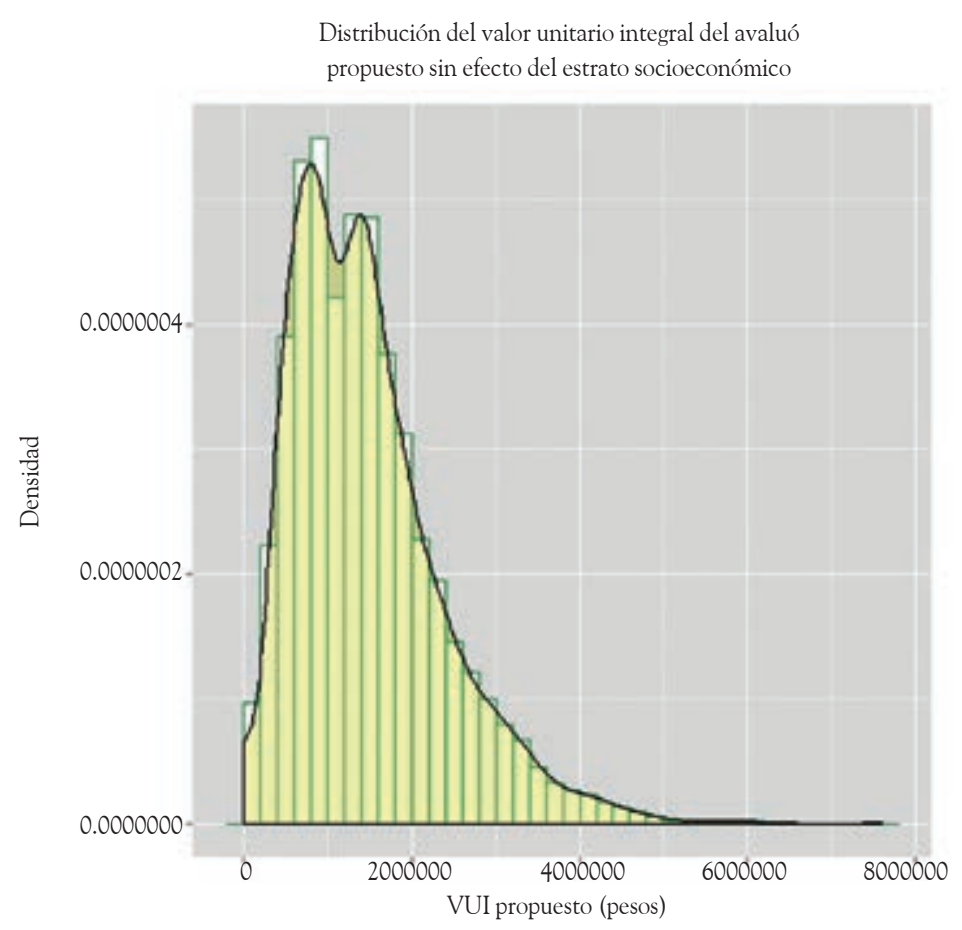

Figura 3.4. Distribución del vUI en pesos (vigencia 2012)

Fuente: elaboración de los autores a partir de la base catastral 2012. 


\subsubsection{EL VALOR UNITARIO INTEGRAL (VUI) VERSUS LA ESTRATIFICACIÓN SOCIOECONÓMICA VIGENTE: UN PANORAMA GENERAL DE LA CIUDAD}

En esta sección, se presenta un análisis comparativo-descriptivo entre la distribución espacial de la variable propuesta de 'valor unitario integral' (VUI) calculada con base en los avalúos e información catastral correspondiente a la vigencia 2012, con respecto a la distribución espacial de la estratificación socioeconómica vigente adoptada en el Decreto 544 de 2012 de la Alcaldía Mayor de Bogotá. La georreferenciación se realiza en términos del promedio del vui y el estrato socioeconómico vigente a nivel de manzana. Los resultados se presentan en la figura 3.5.

Los mapas propuestos permiten comparar la distribución espacial del valor unitario integral clasificado en seis grupos homogéneos (izquierda) y el estrato socioeconómico vigente (derecha). Un análisis de la distribución a nivel de localidades permite encontrar algunos rasgos descriptivos que establecen el comportamiento de cada variable. En primer lugar, se puede apreciar que existe un primer grupo de localidades de Bogotá conformado por Puente Aranda, Los Mártires, Antonio Nariño y Bosa, en las que la estratificación resulta altamente homogénea y clasifica a prácticamente la totalidad de las manzanas en un solo estrato, lo que conduciría a pensar que en el interior de cada una de esas localidades reside un segmento de la población bogotana con condiciones socioeconómicas (y capacidad de pago) muy equiparables. Sin embargo, el mapa de la variable valor unitario integral captura y revela una mayor diferenciación socioeconómica dentro de esas mismas localidades, las cuales detentan desigualdades de precios (y condiciones socioeconómicas de los moradores) de tres o más rangos y, en general, una mayor heterogeneidad socioeconómica que la que propone la estratificación.

En segundo lugar, encontramos otro conjunto más amplio de localidades conformado por Kennedy, Ciudad Bolívar, Tunjuelito, Rafael Uribe Uribe, Usme, San Cristóbal, Santa Fe, La Candelaria, Barrios Unidos, Teusaquillo y Engativá, donde la estratificación sugiere la existencia dominante de dos estratos mayoritarios y una homogeneidad notoria con unos límites físicos entre los dos estratos claramente identificables en el interior de cada localidad. En sentido opuesto, la clasificación obtenida por el valor unitario integral pareciera captar mayores diferencias socioeconómicas en todas estas localidades, con una participación entremezclada de varios rangos de precios y una clasificación de predios y manzanas (por niveles socioeconómicos de sus residentes) 
con límites entre rangos mucho más difusos y difíciles de identificar que los límites mencionados de la estratificación.
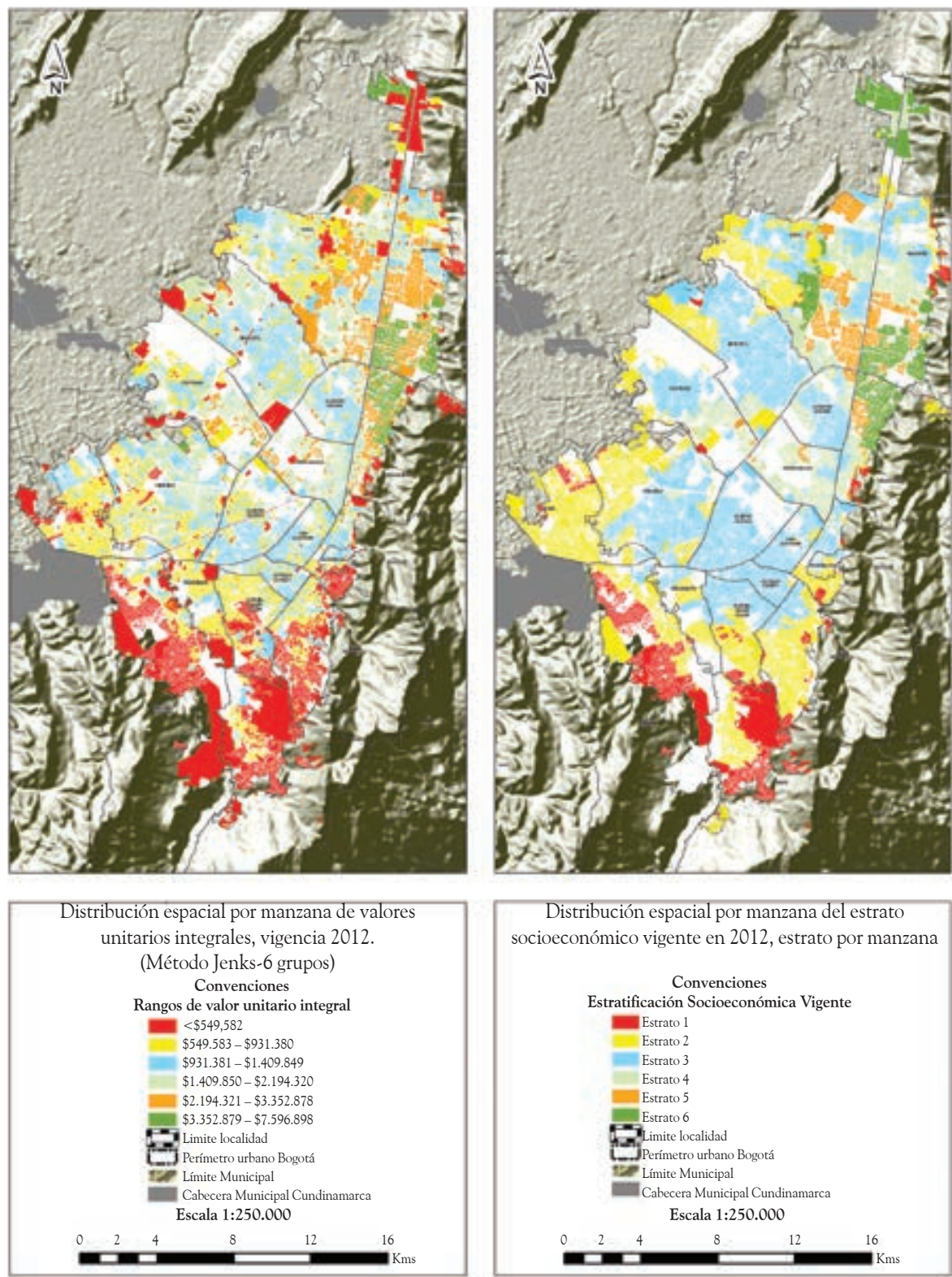

Figura 3.5. Distribución espacial por manzana comparando clasificación por VUI y estratificación vigente

Fuente: elaboración de los autores a partir de la base catastral 2012. 
En tercer lugar, aparece un conjunto de localidades compuesto por Usaquén, Suba, Chapinero y, en menor medida, Fontibón, en los que existe una mayor complejidad en la distribución geográfica de la estratificación, y hay una participación conjunta y simultánea de todos los estratos socioeconómicos, pero con límites bien diferenciados. Allí, el valor unitario integral profundiza tal diferenciación, haciendo más borrosos los límites espaciales entre las manzanas de cada rango de precios, y refleja la existencia de residentes con niveles socioeconómicos muy disímiles dentro de una misma localidad.

Otros aspectos por destacar del análisis comparativo general de la distribución del valor unitario integral respecto de la distribución espacial de la estratificación:

- Se ponen en evidencia un importante número de manzanas con rango de precios muy bajo (valores unitarios integrales menores a $\$ 549.562$, en color rojo), que muestra una mayor presencia de grupos socioeconómicos de baja o nula capacidad de pago en todas las localidades del sur de la ciudad, el cual no es captado por la estratificación socioeconómica vigente.

- En la clasificación por rangos de precios (valor unitario integral), tiende a desaparecer la marcada preponderancia y aglomeración de los grupos socioeconómicos que en la estratificación son clasificados como estratos 2 y 3 , exhibiendo una mayor dispersión urbana de los residentes bogotanos con condiciones socioeconómicas medias-bajas.

- En el norte de la ciudad, las localidades de Chapinero, Usaquén y Suba experimentan una sensible caída en la proporción de manzanas clasificadas según la estratificación en el nivel socioeconómico más alto. Los valores unitarios integrales exponen una baja en esa participación del nivel superior y una disposición espacial mucho más heterogénea de los residentes con mayor capacidad de pago, que la estratificación tiende a homogeneizar.

Es preciso aclarar que la distribución de los valores unitarios integrales empleada en este análisis comparativo no representa la propuesta definitiva presentada a la Administración Distrital, sino que obedece a una primera aproximación de la distribución del valor unitario integral sin el efecto del estrato y al fenómeno de asociación espacial de esta variable con los nive- 
les socioeconómicos; que aún requiere de un análisis de casos atípicos (por ejemplo, de los predios cuyo valor catastral proviene de la práctica de avalúos especiales) y de otras especificidades puntuales en diversos sectores de la ciudad. En los capítulos subsiguientes, se expondrá, con profundo rigor técnico y conceptual, el tipo de procesamiento estadístico, los modelos de clasificación y los resultados finales del uso y tratamiento de la información catastral para la diferenciación socioeconómica en el Distrito Capital.

\section{Reflexiones finales, conclusiones y recomendaciones}

Este capítulo presenta argumentos en pro del uso del avalúo como posible insumo para una nueva estratificación socioeconómica, dada su capacidad de sintetizar las variables de caracterización de la diferenciación socioespacial y que permiten, eventualmente, adelantar una redefinición del fundamento del instrumento.

El uso de variables catastrales, abandonado desde los noventa en los modelos de estratificación diseñada por el DNP, constituye un enfoque viable e idóneo para clasificar y estratificar los domicilios, pretendiendo corregir los errores de inclusión y exclusión vigentes, y garantizando la sostenibilidad del sistema de subsidios y contribuciones a las tarifas de SPD, impactando en un mejor acceso a servicios por parte de los más pobres. La pertinencia del avalúo catastral, aparte de ser una fuente de información técnica y objetiva, tiene, a través de este estudio, un especial interés, ya que, como se verá en el siguiente capítulo, tiene una fuerte asociación con un constructo socioeconómico medido a lo largo de diferentes dimensiones relacionadas con la capacidad de pago y el bienestar medible en los hogares. La cuantificación de dicha relación será el tema central del capítulo 4, abordado desde diferentes métodos estadísticos y apoyado en diversas fuentes de información, como lo es la Encuesta multipropósito de Bogotá, realizada para el año 2011. Cabe resaltar que se han llevado a cabo estudios previos donde la información catastral constituye un acervo de información valiosa desde el punto de vista de su potencialidad para monitorear la dinámica socioeconómica presente en los hogares (DANE, 2011).

La evolución conceptual de la estratificación siempre ha tenido como fundamento la clasificación de las inmuebles residenciales de los usuarios de servicios públicos domiciliarios según las características socioeconómicas de sus habitantes y estas en relación con información que pueda evidenciar tales características. Desde los años setenta, se planteó como base para la 
clasificación de los inmuebles residenciales la información catastral. No obstante, las dificultades que entonces impidieron su utilización se han reducido notablemente y las asociaciones entre la información catastral -más técnica, mejor actualizada y universal para el conjunto de inmuebles de la ciudad-y diversas aproximaciones a la capacidad económica de los usuarios (supuestos o cálculos efectivos sobre el ingreso, el gasto, la capacidad de pago o la calidad de vida) dan cuenta de su idoneidad como acervo de información objetiva para la clasificación.

Se sintetizan enseguida los diversos argumentos que sustentan la tentativa propuesta de utilización de la información catastral como proxy de las características socioeconómicas de los hogares y la forma como esta puede ser soporte idóneo del instrumento de estratificación.

1) El Conpes 3386 de 2005 subraya el riesgo de insostenibilidad del instrumento de estratificación que ha imperado por dos décadas sin modificación. Diversos estudios de diagnóstico resaltan errores de inclusión y exclusión en el esquema vigente, la carencia de información (primaria o secundaria) que permitiera extraer información directa, confiable y estandarizada para clasificar la totalidad de los hogares según sus ingresos y la dificultad del instrumento para actualizarse debido a eventuales costos políticos.

2) La relación entre capacidad de pago y características de la vivienda ha sido sustentada conceptualmente e ilustrada empíricamente en la literatura: en términos generales, los hogares habitan en los lugares que pueden pagar y la diferenciación socioespacial determina la ocupación diferencial del suelo urbano por los distintos grupos sociales en una economía de mercado, a partir de la diferenciación socioeconómica.

3) La información catastral es útil para conceptualizar e implementar esquemas de asignación de tarifas diferenciales que parta de un esquema diferencial dada la capacidad de pago de los hogares. Diversos estudios han presentado ejercicios detallados para Bogotá, que muestran su fuerte correlación y la posibilidad de considerarlo con un insumo pertinente para redefinir el instrumento de estratificación.

4) En la vía de la determinación de una variable que recoja la dinámica socioeconómica de la ciudad, se propone el valor unitario integral obtenido a partir del avalúo catastral, sin embargo, algunos inconvenientes 
relacionados con su cálculo deben ser mencionados, ya que existe una influencia recurrente del estrato socioeconómico como variable de afectación directa en la determinación del avalúo. Se mencionan dos tipos de influencia implícita y explícita: la primera se manifiesta en la práctica de los avalúos comerciales por parte de los peritos, en cuyo trabajo subyace una incidencia del estrato socioeconómico al establecer unos topes máximos y mínimos de valor comercial según el estrato en el que se encuentre el inmueble, sesgo que debe evaluarse y corregirse dentro del proceso de capacitación de los avaluadores llevado a cabo por parte de la UAECD. La influencia explícita es corregida a través de la remoción del estrato socioeconómico de los modelos que determinan el VINT y el VM2Const según su régimen de propiedad horizontal. El impacto de esta corrección en la propuesta de una nueva metodología de estratificación basada en el avalúo está dado por el efecto cíclico que puede presentarse entre los problemas del instrumento vigente y alternativas futuras.

5) A la luz de los ejercicios estadísticos realizados para calcular la influencia explícita del estrato socioeconómico en los avalúos, se obtiene un efecto directo del estrato socioeconómico que gira alrededor del $5 \%$ sobre el cálculo de los valores unitarios de construcción. Una reducción del impacto, evidente pero mediada por el valor unitario de terreno, se encuentra alrededor del 0,04\%. Estas sutiles diferencias son susceptibles de ajustarse con la depuración de las variables modeladas o, incluso, con nuevos modelos.

6) Con el propósito de remover la influencia explícita del estrato en los avalúos y aumentar la robustez de un instrumento de estratificación, se propone un mejor modelo desde el punto de vista estadístico, el cual incorpora variables significativas para la explicación de los valores unitarios de construcción que resulta en una variable de vUI sin efecto del estrato socioeconómico. Refiérase al anexo 5 para los detalles de la construcción del modelo propuesto. Esta variable será usada a través de los siguientes capítulos con el objeto de estudiar sus relaciones con el constructo socioeconómico y permitir así una mejor redistribución de los subsidios y contribuciones en materia de SPD. 